\title{
Impacts of the mountain-plains solenoid and cold pool dynamics on the diurnal variation of warm-season precipitation over northern China
}

\author{
Xinghua Bao ${ }^{1,2}$ and Fuqing Zhang ${ }^{2}$ \\ ${ }^{1}$ State Key Laboratory of Severe Weather, Chinese Academy of Meteorological Sciences, Beijing, China \\ ${ }^{2}$ Department of Meteorology, The Pennsylvania State University, University Park, Pennsylvania, USA
}

Correspondence to: Fuqing Zhang (fzhang @ psu.edu)

Received: 29 August 2012 - Published in Atmos. Chem. Phys. Discuss.: 24 October 2012

Revised: 1 May 2013 - Accepted: 14 June 2013 - Published: 23 July 2013

\begin{abstract}
Convection-permitting numerical experiments using the Weather Research and Forecasting (WRF) model are performed to examine the impact of a thermally driven mountain-plains solenoid (MPS) on the diurnal variation of warm-season precipitation over northern China. The focus of the analyses is a 15-day simulation that uses the 8-day average of the NCEP GFS gridded analyses at 00:00 UT between 17 and 24 June 2004 for the initial conditions and the 8-day averages at 00:00, 06:00, 12:00, and 18:00 UT for the lateral boundary conditions. Despite differences in rainfall intensity and location, the control experiment captures the essence of the observed diurnal variation of warm-season precipitation in northern China. Consistent with observations, the simulated local precipitation peak initiates in the afternoon on the eastern edge and the immediate lee of the mountain ranges due to the upward branch of the MPS. The peak subsequently propagates downslope and southeastward along the steering-level mean flow, reaching the central North China Plain around midnight and early morning hours, resulting in a broad area of nocturnal precipitation maxima over the central plains. Sensitivity experiments show that, besides the impact of the MPS, cold pool dynamics play an essential role in the propagation and maintenance of the precipitation peak over the plains.
\end{abstract}

\section{Introduction}

Precipitation is closely related to human activity and is one of atmospheric parameters that are difficult to predict. Furthermore, the latent heat of condensation released from the precipitation is an important energy source for driving the global atmospheric circulation (Nober et al., 2003). The diurnal cycle of precipitation is one of the most basic forms of climate patterns and has a considerable influence on the regional weather and climate (Dai, 2001; Yang and Slingo, 2001; Liang et al., 2004). The diurnal cycle of precipitation is often used to verify weather and climate models (Dai et al., 1999; Lin et al., 2000; Trenberth et al., 2003; Dai and Trenberth, 2004). Under the influences of both the eastern Asia monsoon climate (Tao and Chen, 1987) and complex topography, there are clear seasonal and regional changes in the diurnal cycle of precipitation over eastern Asia. Recent studies have investigated the diurnal variation of precipitation over eastern Asia, including different regions of China (Ohsawa et al., 2001; Wang et al., 2004, 2005; Hirose and Nakamura, 2005; Yu et al., 2007a, b; Li et al., 2008; Xu et al., 2009; Huang et al., 2010; He and Zhang, 2010, hereafter referred to as HZ10; Bao et al., 2011; Sun and Zhang, 2012).

The diurnal variation of precipitation is often induced by differential diabatic heating between regions with different surface topography. Several recent studies have focused on the diurnal cycle of precipitation over the large mountains and adjacent plains/basins (e.g., Carbone et al., 2002; Wang et al., 2004, 2005; Yu et al., 2007a, b; Fitzjarrald et al., 2008; Laing et al., 2008; Levizzani et al., 2010; Huang et al., 2010; HZ10; Bao et al., 2011; Sun and Zhang, 2012). Most of these studies have found that the diurnal cycle of precipitation is strongly associated with the thermally driven regional mountain-plains solenoid (MPS) circulation, with the diurnal precipitation peaks initiating on the top or lee of the mountains in the afternoon and then propagating to the 

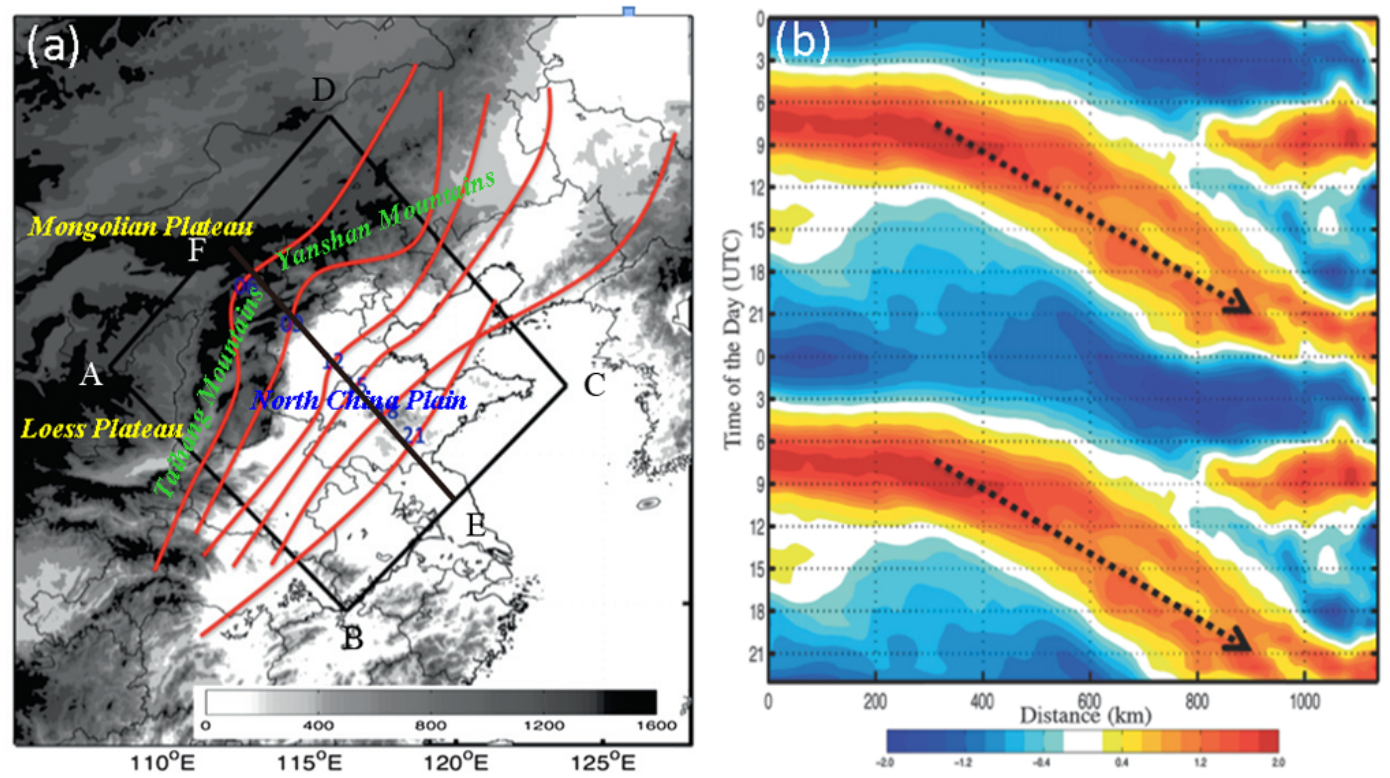

Fig. 1. (a) Isochrones (phase fronts) of the local diurnal precipitation peaks at different times with terrain elevation shaded every $200 \mathrm{~m}$. The labels of the isochrones are in UT ( $8 \mathrm{~h}$ behind the local standard time, Beijing time). From Fig. 2b of HZ10. (b) Distance-time Hovmöller diagram of the normalized hourly precipitation deviation without filtering averaged along the northwest-southeast cross section within the black box in (a). The dashed arrows show the southeastward phase propagation of the diurnal precipitation peaks. From Fig. 4 of HZ10.

plains during the night. The evolution of the MPS circulation near large-scale mountains - including the Rockies in North America and the Tibetan Plateau in eastern Asia (as well as their adjacent plains) - has been studied extensively. In addition, existing observation networks or analysis datasets are unable to resolve the MPS structure and evolution, as well as the interactions of the MPS and the diurnal precipitation, in detail. High-resolution simulations have already been used to analyze the evolution of the MPS circulation near different mountain ranges (e.g., Tripoli and Cotton, 1986, 1989; Wolyn and McKee, 1994; Zhang and Koch, 2000; Koch et al., 2001; Carbone and Tuttle, 2008; Trier et al. 2006, 2010; Li and Simith, 2010; Pritchard et al., 2011; Laing et al., 2012).

In China, the terrain height decreases from west to east in a three-step pattern. The Tibetan Plateau is the first step, and has a mean elevation greater than $4500 \mathrm{~m}$. The second step is located to the east and north of the Tibetan Plateau and includes large-scale basins and several plateaus, with elevations between 1000 and $2000 \mathrm{~m}$. A northeast-southwestoriented mountain line (which includes the Great Khingan, Taihangshan Mountain, Wushan Mountain and Xufeng Mountain) divides the second and third steps. The third step consists of plains and hills with a mean elevation of less than $500 \mathrm{~m}$. Due to the strong heating effect of the Tibetan Plateau on the regional weather and climate, most studies on the diurnal cycle of precipitation focus on the Tibetan Plateau and the adjacent lee regions with lower terrain. These studies found that the diurnal precipitation peak usually begins over the Tibetan Plateau in the early afternoon and then propagates eastward (Asai et al., 1998; Wang et al., 2004, 2005; Fujinami et al., 2005; Yu et al., 2007a; Zhou et al., 2008; Chen et al., 2009a, b; Xu and Zipser 2011; Bao et al., 2011). The plateaus and mountains of the second step also have an important influence on the local diurnal variation of precipitation: because they are much higher than the plains of the third step, the differential solar heating rate between these two steps yields a temperature gradient that can give rise to the MPS circulation. Nevertheless, only a few studies have explored the relation of MPS circulation and diurnal precipitation variations with a focus on these second and third steps over China (HZ10; Bao et al., 2011; Sun and Zhang, 2012).

HZ10 explored the diurnal variations of warm-season precipitation over northern China using the CMORPH dataset and the NCEP GFS analysis. Figure 1a (Fig. 2b from HZ10) shows the phase fronts of the warm-season diurnal precipitation peaks at different times from CMORPH observations, whereas Fig. 1b (Fig. 4 from HZ10) shows the distance-time Hovmöller diagram of the normalized hourly precipitation deviation averaged along a northwest-southeast cross section in the focus domain. HZ10 found that the diurnal precipitation peaks initiate over the mountains in the early afternoon and then propagate downslope and southeastward to the plains at a speed of $\sim 13 \mathrm{~m} \mathrm{~s}^{-1}$ (Fig. 1b), and that the diurnal variation of the MPS circulation is one of the important factors on the diurnal cycle of precipitation. But HZ10 did not investigate the detailed evolution of the MPS or its influence on the diurnal variation in precipitation because of the coarse temporal and spatial resolution of their dataset. 


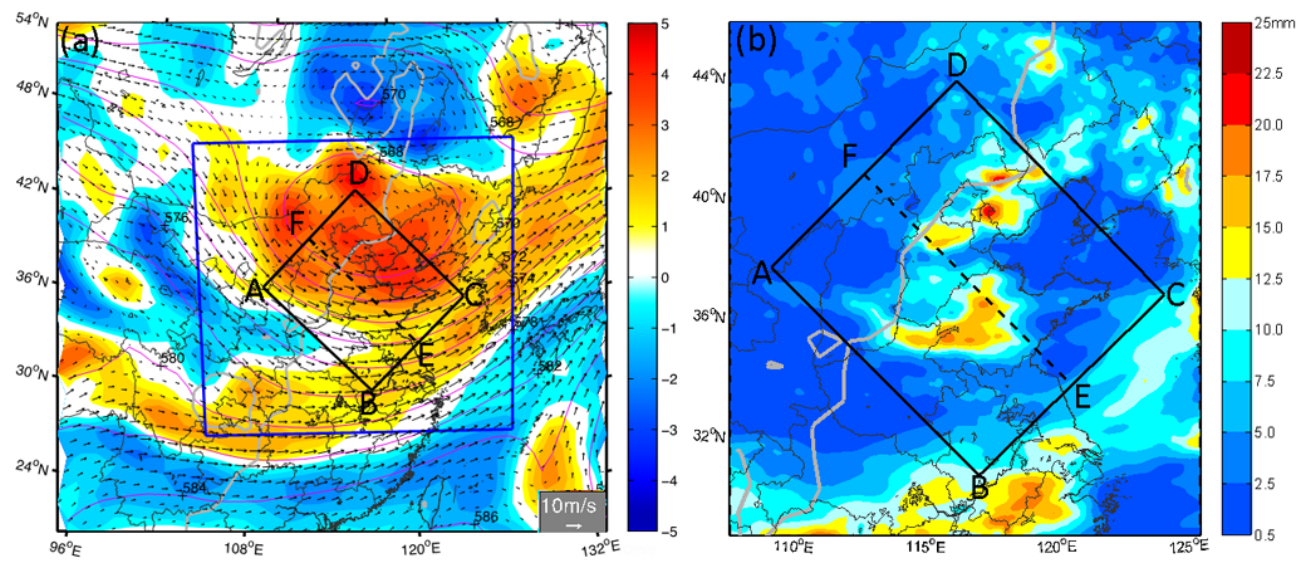

Fig. 2. (a) The average $500 \mathrm{hPa}$ relative vorticity $\left(10^{-5} \mathrm{~s}^{-1}\right.$, shaded), horizontal wind vectors, and geopotential height every 2 dam (magenta contours) between 00:00 UT on 17 June and 00:00 UT on 24 June 2004 from GFS analysis. The blue box is the simulation domain. The rectangle $\mathrm{ABCD}$ indicates the focus area, and the dashed line $\mathrm{EF}$ divides $\mathrm{ABCD}$ into north and south domains. (b) Average daily precipitation $(\mathrm{mm})$ between 17 and 24 June from CMORPH.

The current study follows HZ10 but uses higher-resolution numerical simulations to try to determine the causes of the diurnal variation in precipitation over northern China and the influence of the MPS circulation (between the aforementioned second and third steps). The current work also complements the recent high-resolution modeling study of Sun and Zhang (2012) which examined the impact of the MPS on the diurnal variations of precipitation and mesoscale convective vortices along the mei-yu front over the East China Plains.

To be consistent with HZ10, the focus area of this study is over the Yanshan-Taihangshan mountain ranges along the eastern peripheries of the Loess-Mongolian plateaus and the adjacent North China Plain (Fig. 1a); here, the terrain decreases from northwest to southeast in a two-step pattern. The Weather Research and Forecasting (WRF) modeling system is used to simulate the propagation of the diurnal precipitation peak during the period of 17-24 June 2004. The primary objective of the current study is to examine the impacts of the MPS on the diurnal variation of precipitation over northern China. Section 2 provides a description of the experimental design. Section 3 presents an overview of the simulations and a comparison with the observations. The interactions of the MPS circulation and the diurnal precipitation variation over northern China are discussed in detail in Sect. 4. Two sensitivity tests with respect to latent heating and cooling are reported in Sect. 5. Section 6 gives the concluding remarks of the study.

\section{Numerical model and experimental design}

Version 3.2 of the Advanced Research WRF (WRF-ARW) model (Skamarock et al., 2008) is employed in this study. The National Centers for Environmental Prediction (NCEP)
Global Forecast System (GFS) Final (FNL) $1^{\circ} \times 1^{\circ}$ operational analyses every $6 \mathrm{~h}$ are used to produce the initial and lateral boundary conditions. The experimental runs all have one domain that covers northern China and adjacent areas with $749 \times 701$ horizontal grid points and $3 \mathrm{~km}$ grid spacing (Fig. 2a). There are 31 vertical levels, with the top at $50 \mathrm{hPa}$. The model employs the Yonsei University (YSU) PBL scheme (Hong et al., 2006), the RUC land surface model, and the Rapid Radiative Transfer Model longwave (Mlawer et al., 1997) and Dudhia (1989) shortwave radiation schemes. The WSM6 scheme is used for the microphysics parameterization (Hong and Lim, 2006). No cumulus parameterization is used.

The primary goal of the experiments is not to recreate any single precipitation episode, but to capture more general characteristics of the diurnal cycle of warm-season precipitation over northern China and to examine the influence of the MPS. We choose 17-24 June 2004 as the study period because there were several observed diurnally recurring episodes of precipitation propagating from the mountains to the plains (Fig. 3a). A distance-time Hovmöller diagram of the rain rate averaged along the northwest-southeast cross section over the region ABEF (see Fig. 2b) between 00:00 UT on 17 June and 00:00 UT on 25 June 2004 from CMORPH data (Fig. 6a) shows a similar feature of the diurnal cycle of warm-season local precipitation (Fig. 1b).

Table 1 lists the experiments conducted in this study and gives a brief description of each. The experiment REAL is initialized at 00:00 UT on 17 June 2004 with the lateral boundary conditions updated every $6 \mathrm{~h}$ provided directly by the reanalysis from 00:00 UT on 17 June to 00:00 UT on 25 June 2004. Following Trier et al. (2010) and Sun and Zhang (2012), a 15-day diurnal control experiment (CNTL) is run in order to reproduce the diurnal variation of precipitation and research how the MPS influences the diurnal 

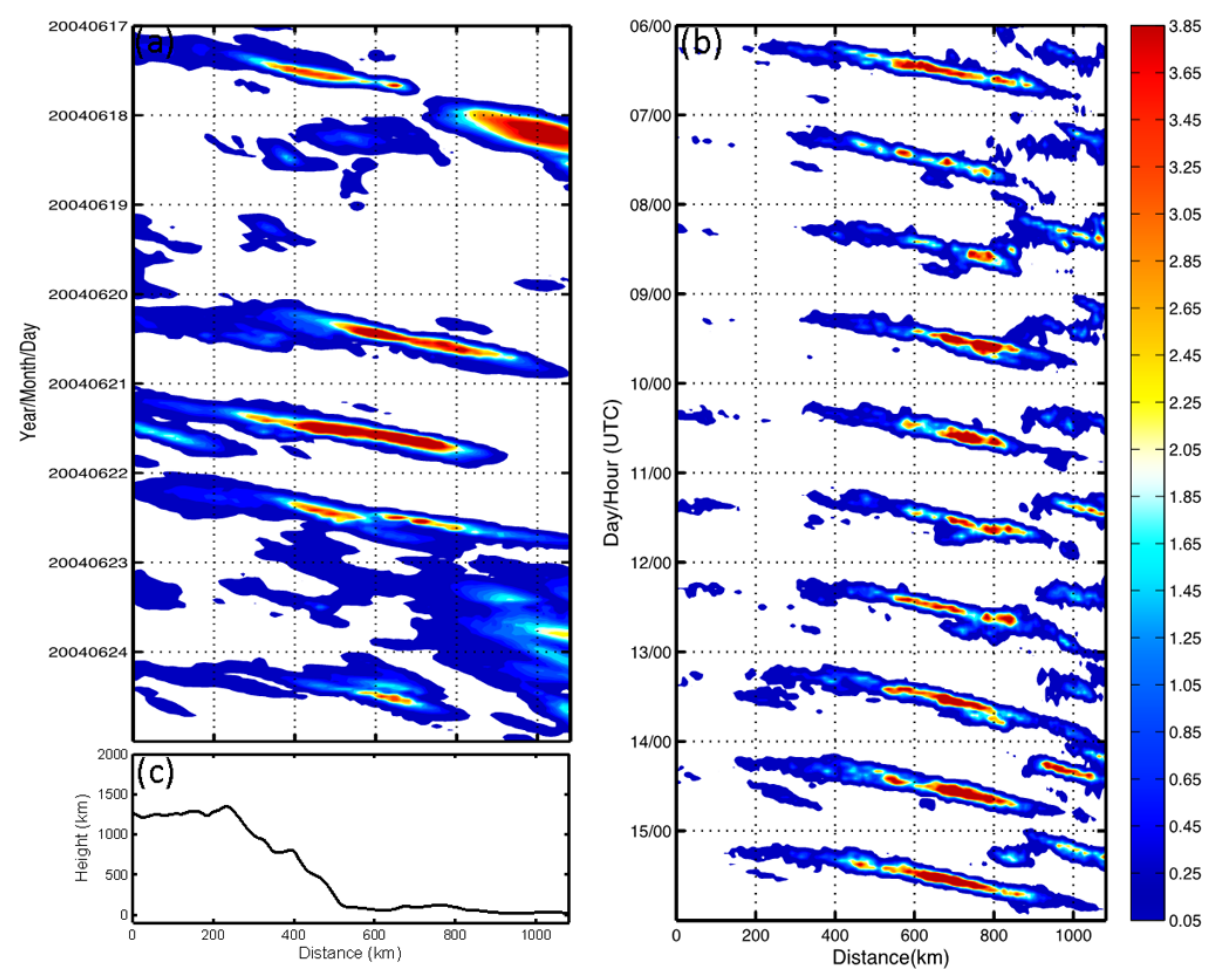

Fig. 3. Hovmöller diagram of the rain rate $\left(\mathrm{mm} \mathrm{h}^{-1}\right)$ averaged along the northwest-southeast cross section over $\mathrm{ABEF}$ for (a) 1724 June 2004 from CMORPH and (b) the final 10 days of the control simulation (CNTL). (c) Averaged terrain elevation along the northwestsoutheast direction over ABEF.

precipitation cycle. The CNTL experiment is initialized using the 8-day (17-24 June 2004) averaged 00:00 UT GFS analyses, with lateral boundary conditions derived from the 8-day averaged 00:00 UT, 06:00 UT, 12:00 UT, and 18:00 UT GFS analyses.

Two sensitivity experiments are designed to examine the impact of latent heating and cooling on the diurnal variation and propagation of the local peak precipitation. The experiment "Fake-dry" includes 10 consecutive $24 \mathrm{~h}$ simulations configured the same as CNTL except that all forms of latent heating and cooling (between ice, liquid, and vapor) are turned off; each simulation is initialized with the 00:00 UT forecast of the last 10 days of the CNTL simulation ${ }^{1}$. The experiment "NOVAP" is also configured the same as CNTL except that only the cooling associated with the evaporation of liquid water is turned off, which essentially shuts off the mechanisms for cold pool formation from moist convection.

\footnotetext{
${ }^{1}$ Another sensitivity experiment was performed that completely eliminates moist convection during the entire 15-day simulation. However, since the large-scale circulation is drastically different from that in the CNTL, this simulation is not further discussed. There are also apparent inconsistency and discontinuity between this 15-day continuous dry simulation and the boundary conditions derived from the fully moist reanalysis used in CNTL. Nevertheless, we found no evidence that the MPS in this longer-term continuous simulation is stronger than that in the current Fake-dry experiment.
}

\section{The simulated results and comparison with observations}

Figure 2a shows the 8-day 00:00 UT average of the $500 \mathrm{hPa}$ relative vorticity, horizontal wind, and geopotential height derived from the FNL analyses during the period of 17 24 June 2004. A quasi-steady low-pressure system - often referred to as China's "Northeast Cold Vortex" (NECV) - is located to the north of the focus domain (box ABCD). This subsynoptic cut-off low is one of the most important warmseason rain producers over northern and northeastern China (Zhang et al., 2008; Hu et al., 2010). Over this 8-day period, under the influence of NECV, the flow is predominantly northwesterly over the southwestern half of the focus domain (box ABEF). We believe it is not so much the presence of the NECV circulation but the persistence and prevalence of the northwesterly flow across the mountains and plains over northern China that is important for the current study. Using $7 \mathrm{yr}$ observational analyses (CMORPH and FNL), He and Zhang (2010) showed that southeastward propagation of diurnal precipitation is quite common in warm seasons under cross-mountain northwesterlies, with and without the NECVs. Figure $2 \mathrm{~b}$ shows the observed daily-mean precipitation averaged over the 8-day period from the $\mathrm{CMORPH}^{2}$

2 The high-resolution global precipitation dataset from the NOAA Climate Prediction Center's morphing technique 
Table 1. Summary of WRF numerical experiments.

\begin{tabular}{|c|c|c|c|c|c|}
\hline Expt & Objectives & $\begin{array}{l}\text { Forecast lengths } \\
\text { and number of runs }\end{array}$ & Initial condition & $\begin{array}{l}\text { Lateral boundary } \\
\text { condition }\end{array}$ & Description \\
\hline REAL & $\begin{array}{l}\text { Real data simulation for } \\
8 \text { days }\end{array}$ & $\begin{array}{l}\text { One 8-day } \\
\text { continuous run }\end{array}$ & $\begin{array}{l}\text { 00:00 UTC, } \\
17 \text { June } 2004\end{array}$ & $\begin{array}{l}\text { Real data from } \\
\text { 00:00 UTC, } \\
\text { 17:00-00:00 UTC, } \\
\text { 25 June 2004 }\end{array}$ & Full physics \\
\hline CNTL & $\begin{array}{l}\text { Sensitivity to diurnal } \\
\text { cycle and initial } \\
\text { conditions }\end{array}$ & $\begin{array}{l}\text { One 15-day } \\
\text { continuous run }\end{array}$ & $\begin{array}{l}\text { The mean of } \\
\text { 00:00 UTC from } 17 \text { to } \\
\text { 24 June } 2004\end{array}$ & $\begin{array}{l}\text { The means of } \\
\text { 00:00, 06:00, } \\
\text { 12:00, and } \\
\text { 18:00 UTC } \\
\text { between } \\
\text { 17 and } \\
\text { 24 June } 2004\end{array}$ & As in REAL \\
\hline
\end{tabular}

dataset. There are two rainfall maxima in ABCD: one to the north over the immediate foothills of the northern mountain ranges, and the other to the south over the center of the North China Plain. We will focus on ABEF because the southern rainfall maximum results primarily from the daily and nocturnal precipitation peaks.

\subsection{Overview of the rainfall simulations}

The observational rainfall data from CMORPH (Fig. 2b) is compared with the mean daily precipitations of the four experiments: the 8 days of REAL, the last 10 days of CNTL (the first 5 days are ignored to lessen the sensitivity to the initial conditions), and the 10 consecutive $24 \mathrm{~h}$ forecasts of Fake-dry and NOVAP (Fig. 4). As a whole, REAL reproduces the overall features of rainfall over northern China, but shows less intense precipitation in the southeastern region (Fig. 4a). Despite slightly stronger intensity and smaller coverage, CNTL simulates reasonably well the maximum rainfall area in the southern domain. However, the northern rainfall in this experiment occurs to the east of the rainfall estimated by CMORPH (Fig. 2b); this difference is likely

(CMORPH, Joyce et al., 2004) with a spatial resolution of $0.07277^{\circ}$ is used as the observation. CMORPH has been verified with Chinese rain gauge reports from $\sim 2000$ stations and exhibits the best performance among satellite precipitation estimates in depicting the spatial and temporal variations of precipitation (Shen et al., 2010). The CMORPH dataset is used to study the diurnal cycle of precipitation over different domains of China (e.g., HZ10; Bao et al., 2011; Sun and Zhang, 2012). due to the impact of the transient weather systems embedded within the NECV that are purposely filtered out for the control simulations. The intensities and locations of rainfall in experiments Fake-dry and NOVAP (Fig. 4c and d) are quite different from each other (as well as both REAL and CMORPH observations). For CNTL, precipitation covers the whole southeast region and the maximum daily precipitation occurs over the plains. In Fake-dry, the precipitation is much less than that of CNTL, is barely existent near the mountains, and essentially disappears over the plains in the south region. In NOVAP, on the other hand, the precipitation is about four times larger than that of CNTL; apart from the plains, another maximum in daily precipitation is located on the southeast edge of the south domain. The local convection is enhanced in the absence of evaporative cooling. Thus, turning off evaporative cooling (NOVAP) significantly increases precipitation, but turning off both heating and cooling for all phase changes (Fake-dry) yields a large decrease in precipitation. Overall, latent heating and cooling make a significant contribution to the initiation and intensity of precipitation over northern China, especially over the plains.

\subsection{The diurnal cycle of simulated precipitation}

Figure 3a shows a Hovmöller diagram of rain rate averaged along a northwest-southeast cross section in ABEF (marked in Fig. 2b) for CMORPH observations during the period of 17-24 June 2004. Consistent with the warm-season average from HZ10, there are at least five episodes of diurnally varying southeastward-propagating rain streaks during this 


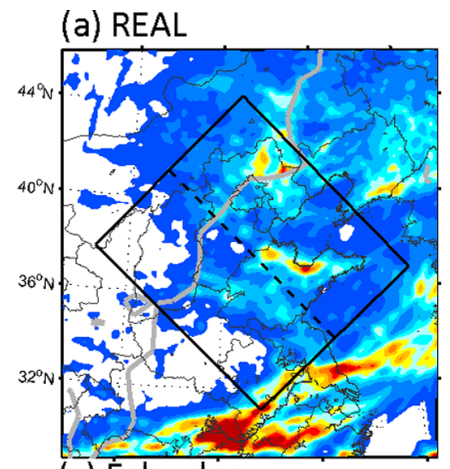

(c) Fake-dry

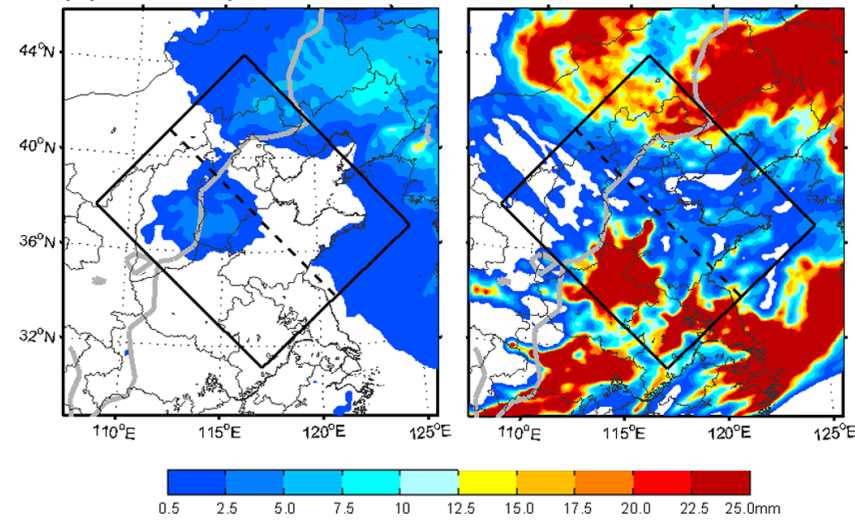

Fig. 4. Mean daily precipitation (mm) for (a) REAL; (b) CNTL; (c) Fake-dry; (d) NOVAP.

8-day period, with rainfall peaks beginning near the eastern top of the mountain ranges in the afternoon and subsequently propagating southeastward to the plains overnight. Figure $3 \mathrm{~b}$ shows the corresponding Hovmöller diagram for the last 10 days of the control experiment. As in Trier et al. (2010) and Sun and Zhang (2012), with diurnally varying boundary conditions and after a 5-day spin-up period, the southeastward-propagating rain streaks become more regular and occur every day for the last 10 days of CNTL. These streaks take around $18 \mathrm{~h}$ to propagate from near the eastern top of the mountain ranges in the afternoon to the southeast edge of the focus domain in the morning, with a phase speed of $\sim 12 \mathrm{~m} \mathrm{~s}^{-1}$. This is approximately the mean steering flow speed in the mid-levels, and is also similar to the $7 \mathrm{yr}$ warmseason average in HZ10 over this area. As shown in Fig. 1, HZ10 found the propagation speed of diurnal precipitation peak to be $\sim 13 \mathrm{~m} \mathrm{~s}^{-1}$.

The experiment CNTL reproduces the diurnal variations of precipitation over northern China. In order to present the diurnal variations of precipitation in detail, Fig. 5a-h show the diurnal hourly precipitation rate averaged over the final 10 days at different times. Similar to Fig. 1a from HZ10, Fig. 5i uses isochrones to depict the locations of the diurnal precipitation peak for the different hours shown in Fig. 5a-h. The diurnal rainfall belt starts in the early afternoon (around 06:00 UT, or 14:00 Beijing Standard Time
(BST)) on the lee of the mountain ranges. The rainfall belt intensifies as it heads downward along the eastern slope of the mountain ranges, and reaches the peak intensity on the western edge of the plains between 12:00 and 15:00 UT (20:00 and 23:00 BST). Propagating toward the southeast, the rainfall belt starts its gradual weakening just before midnight (15:00 UT, or 23:00 BST) over the center of the plains; the belt reaches the eastern edge of the focus domain between 21:00 and 00:00 UT (05:00 and 08:00 BST), by which time the diurnal rainfall has almost completely faded away (Fig. 5a and h). There are different propagation features between the north and south regions (separated by the dashed line EF in Fig. 2b). It is clear that the diurnal precipitation variations in the south region are more similar to that of warm-season as in HZ10. This is the primary reason why we focus on the southern region (ABEF) to analyze the impact of the MPS on the diurnal variation in precipitation.

To further elucidate the diurnal variation and propagation features of the precipitation over northern China from the different experiments, Hovmöller diagrams of the mean hourly precipitation along the northwest-southeast cross section in ABEF averaged over 8 days for CMORPH, the simulated final 10 days for CNTL, and the simulated 10 days for Fakedry and NOVAP are shown in Fig. 6. Consistent with the daily evolutions in Fig. 3b, the main characteristics of the mean diurnal cycle in CNTL (Fig. 6b) are broadly similar to those in CMORPH (Fig. 6a). The average phase speed of the southeastward-propagating rain belt is $\sim 12 \mathrm{~m} \mathrm{~s}^{-1}$, which is similar to the observed climatological dirunal propagation phase speed estimated by HZ10. CNTL represents the main characteristics of the diurnal cycle described by HZ10 in terms of both timing and propagation, although the strongest rainfall happens over the central plains just before midnight (around 15:00 UT, or 23:00 BST, Fig. 6b) instead of over the foothills of the mountains in the evening hours in CMORPH observations (around 12:00 UT, or 20:00 BST, Fig. 6a). CNTL also reproduces well the diurnal variations of precipitation over ABEF. In the Fake-dry experiment, the diurnal precipitation is much weaker and is confined to the area just near the mountains in the late afternoon and the night (rather than propagating southeastward). In the NOVAP experiment, the mean diurnal precipitation is substantially higher than that of CNTL over the plains on the center and southeast edge of ABEF; unlike Fake-dry, NOVAP preserves the characteristics of the diurnal propagation (albeit with a speed of $\sim 9 \mathrm{~m} \mathrm{~s}^{-1}$ ).

\section{The MPS circulation and the diurnal precipitation variations over northern China}

As discussed before, the diurnal control experiment broadly reproduces (in agreement with HZ10) the diurnal variation of precipitation and southeastward propagation of the peak phase of the diurnal precipitation from the lee of 
(a) 00UTC (08BST)

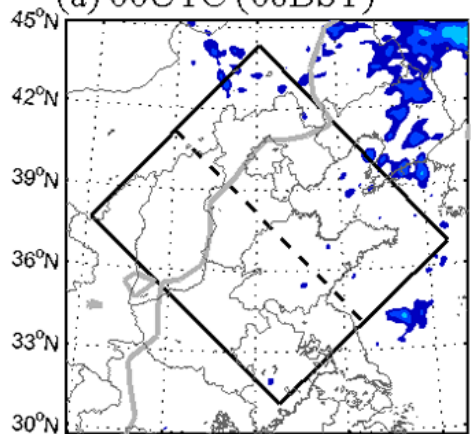

(d) 09UTC (17BST)

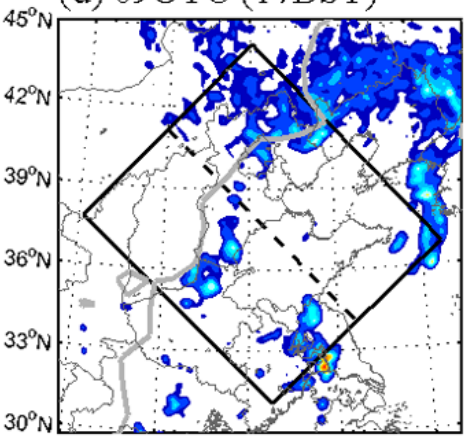

(g) $18 \mathrm{UTC}(02 \mathrm{BST})$
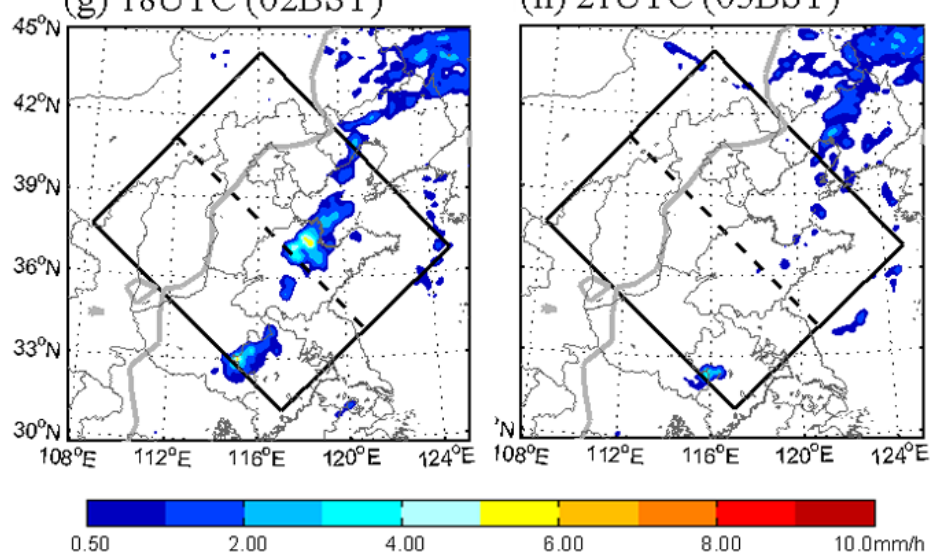

(b) 03UTC (11BST)

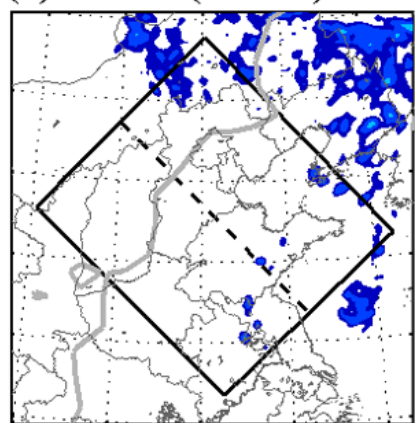

(e) 12UTC (20BST)

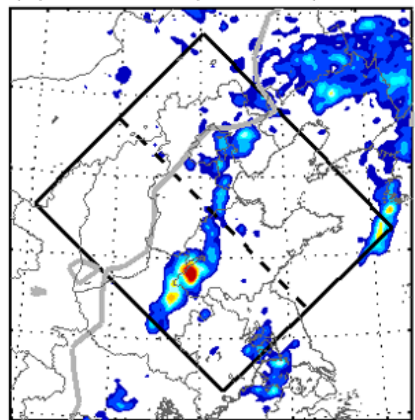

(h) 21UTC (05BST)

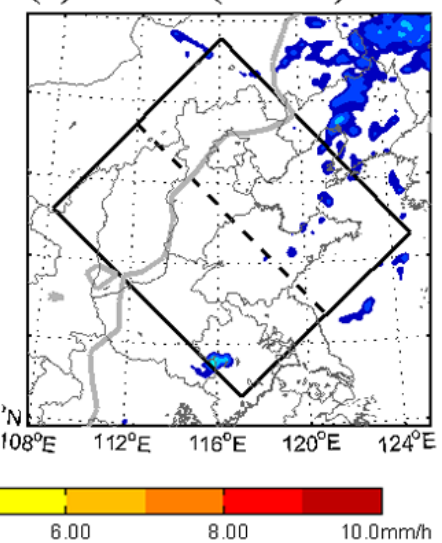

(c) 06UTC (14 BST)

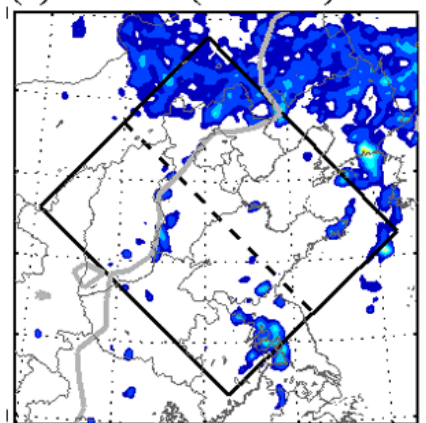

(f) 15UTC (23 BST)

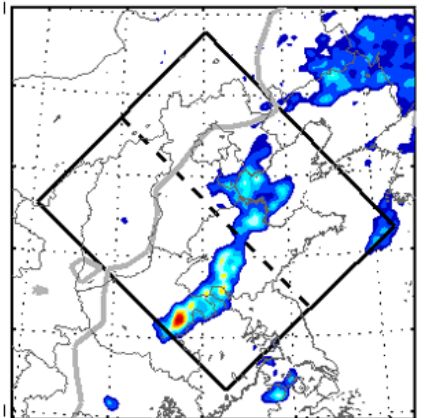

(i)

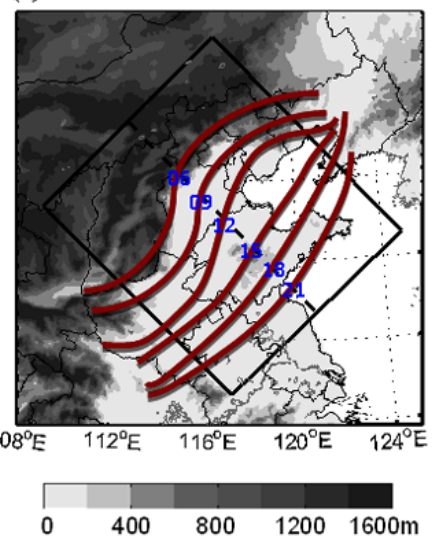

Fig. 5. Spatial distribution of diurnal hourly precipitation rate for final 10 days of CNTL at (a) 00:00 UT; (b) 03:00 UT; (c) 06:00 UT; (d) 09:00 UT; (e) 12:00 UT; (f) 15:00 UT; (g) 18:00 UT; and (h) 21:00 UT. (i) Isochrones (phase fronts) of the local diurnal precipitation peaks at different times with terrain elevations shaded every $200 \mathrm{~m}$. The isochrones are labeled in UT.

Yanshan-Taihangshan mountain ranges to the North China Plain over northern China. Using the rather coarse temporal and spatial resolution of the GFS analysis, HZ10 found that the MPS circulation has a close connection with the diurnal variation of warm-season precipitation over northern China. To analyze the characteristics of the MPS circulation in further detail, the results of the CNTL, Fake-dry and NOVAP experiments are compared and discussed.

\subsection{The average MPS circulation and the diurnal variations of the MPS updraft}

Figure 7 shows the mean and anomalous horizontal and vertical velocities at $3 \mathrm{~km}$ from the CNTL simulation. In order to ignore small-scale disturbances, scales smaller than $200 \mathrm{~km}$ are truncated in this figure with the same 2-D spectral decomposition technique used by HZ10. Height-distance cross sections of mean and anomalous winds and potential temperature are shown in Fig. 8.

The average circulation over the last 10 days of CNTL (Fig. 7a) is similar to the initial circulation (Fig. 2a). Under the influence of the NECV in the northeast of the domain, 
(a) CMORPH

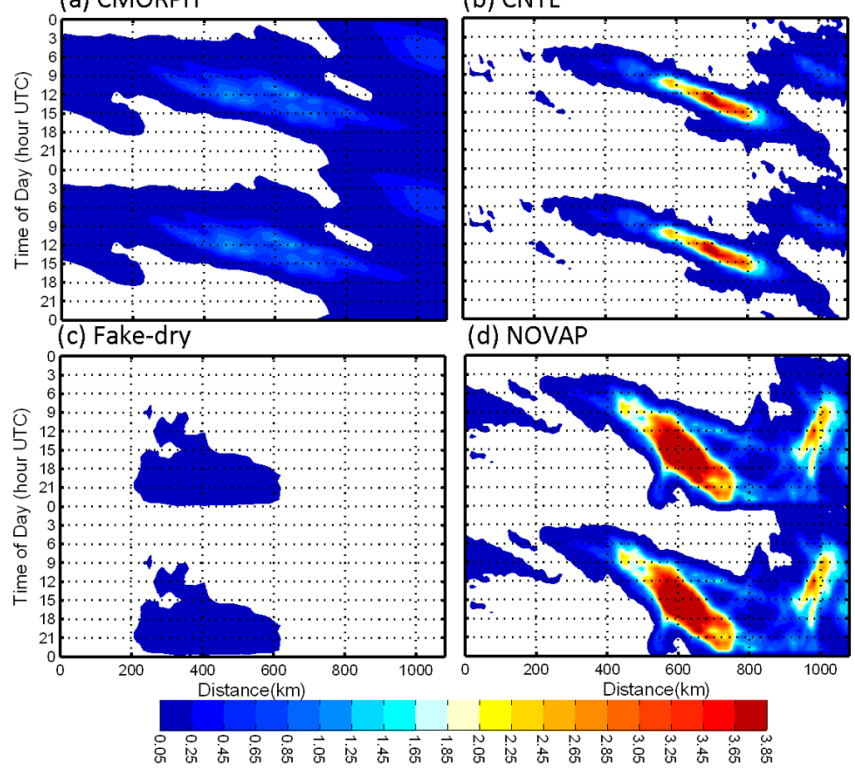

Fig. 6. Hovmöller diagram of the rain rate $\left(\mathrm{mm} \mathrm{h}^{-1}\right)$ averaged along the cross northwest-southeast cross section over ABEF for (a) 1724 June 2004 from CMORPH; (b) the final 10 days of CNTL; (c) the 10 days of Fake-dry; (d) the 10 days of NOVAP.

northwesterly flow dominates over the south region (ABEF). Intense ascending motion (as high as $5 \mathrm{~cm} \mathrm{~s}^{-1}$ ) is located near the mountains, whereas the vertical motion over the plains is weak (in the range of -1 to $1 \mathrm{~cm} \mathrm{~s}^{-1}$ ). The average northwesterly component of wind speed increases gradually with height (Fig. 8a).

Consistent with the southeastward movement of diurnal precipitation peaks, an obvious belt of anomalous upward motion is located along the mountains around 06:00 UT (14:00 BST) and then propagates southeastward to the plains (Figs. $7 \mathrm{~d}$ and $8 \mathrm{~d}$ ). A downdraft belt divides the updraft into two parts at 09:00 UT (17:00 BST, Figs. 7e and 8e), with the stronger one arriving at the northwest edge of the plains, and the weaker one remaining near the mountains. The updrafts are separated by $6 \mathrm{~h}$ in time or $300 \mathrm{~km}$ in distance. All vertical motions weaken by the early morning (18:00 UT, or 02:00 BST). The main updraft gets to the southeast edge of ABEF, while the secondary updraft arrives at the central plains. At this time, the downward motion deviation begins to appear near the top of mountains (Figs. $7 \mathrm{~h}$ and $8 \mathrm{~h}$ ). Three hours later (21:00 UT, or 05:00 BST), the main updraft moves out of this south region and the secondary updraft reaches the southeast plain, downdraft appears on and near the mountains (Figs. 7i and 8i). The main updraft is primarily responsible for the occurrence of the diurnal precipitation and the southeastward propagation of the rainfall belt.

\subsection{Diurnal variation of the MPS circulation and its impacts}

Past studies have found that the diurnal cycle of the MPS is composed of four stages: developing and peak daytime and nighttime phases (Wolyn and McKee, 1994; Zhang and Koch, 2000; Koch et al., 2001; Huang et al., 2010; Sun and Zhang, 2012). HZ10 discussed the characteristics of the MPS during these four different stages over northern China. The peak daytime phase is during the afternoon, coincident with the maximum solar heating. At this time, the MPS updraft is located over the top and the slope of the mountain ranges, while the MPS downdraft is located over the plains. The peak nighttime phase is almost the reverse of the peak daytime phase.

In order to reveal the diurnal variation in the evolution of the MPS circulation, Fig. 8b-i show (at $3 \mathrm{~h}$ intervals) the potential temperature and deviations from the daily mean of the three-dimensional circulation along the northwest-southeast cross section averaged over ABEF of experiment CNTL.

A few hours after sunrise (00:00 UT, or 08:00 BST, Fig. 8b), the MPS is still mostly in the nighttime phase, with the updraft over the plains (the maximum is over the southeastern plains) and the downdraft near the Taihang Mountain Range. Above $2 \mathrm{~km}$, the wind is southeasterly, whereas below $2 \mathrm{~km}$ the wind is northwesterly. At 03:00 UT (11:00 BST, Fig. 8c), solar radiation (and therefore surface heating) begins to increase. Consequently, the mountains are heated more than the plains, reversing the direction of the temperature gradient and transforming the MPS from the nighttime pattern to the daytime pattern. The downward motion occurs near the top and the slope of the mountains, and the upward motion diminishes further. The phenomenon illustrates that MPS circulation is in the developing daytime phase (Fig. 8c).

In the early afternoon (06:00 UT, or 14:00 BST, Fig. 8d), near the time of maximum solar heating, the daytime temperature gradient between mountains and plains is at its strongest. Surface solar heating over the mountain ranges and the adjacent slopes has driven a flow reversal from the nighttime pattern, with upslope flow now prevailing in the lee of mountains. Because the temperature over mountains is higher than that over the plains, the MPS is in the peak daytime pattern with the main updraft U1 near the southeast slope of mountains and the main downdraft over the plains. This daytime pattern of the MPS circulation is characterized by a low-level upslope southeasterly flow and a reversed return flow in the mid-levels. At this time, the strong updraft associated with the MPS circulation triggers rain along the lee slope of the mountains.

In the late afternoon (09:00 UT, or 17:00 BST, Fig. 8e), the updraft intensifies as it moves down the southeast slope of the mountains. Latent heat release causes the moist air in the rising branch to warm, which enhances the vertical motion and results in heavier rainfall behind the main updraft U1. Evaporative cooling caused by the falling precipitation 
(a) average

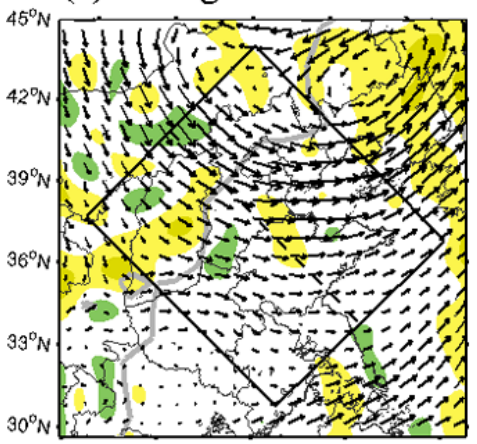

(d) 06UTC (14 BST)

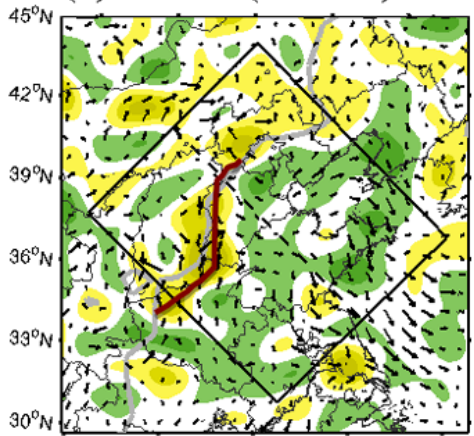

(g) $15 \mathrm{UTC}(23 \mathrm{BST})$

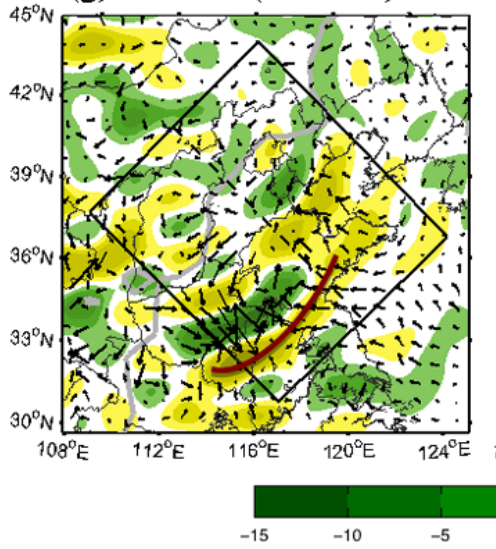

(b) 00UTC (08BST)

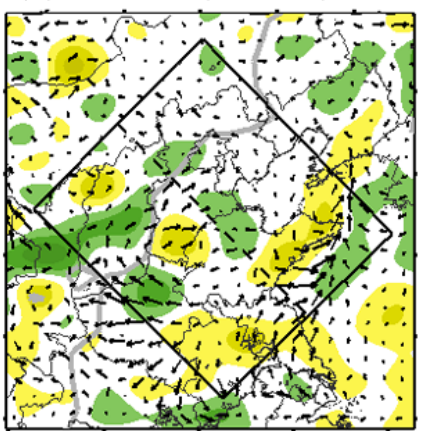

(e) 09UTC (17BST)

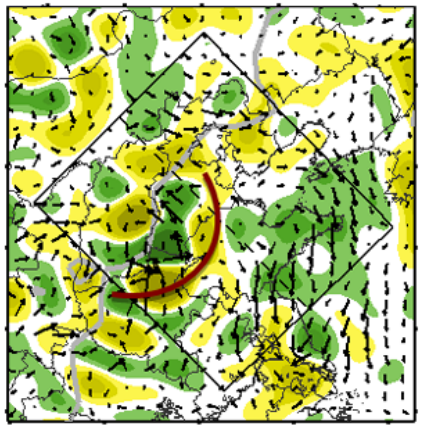

(h) 18UTC (02BST)

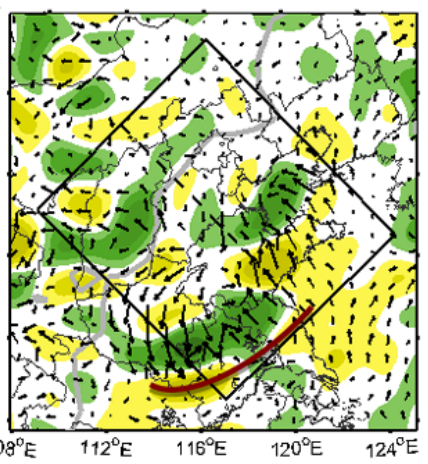

(c) 03UTC (11BST)

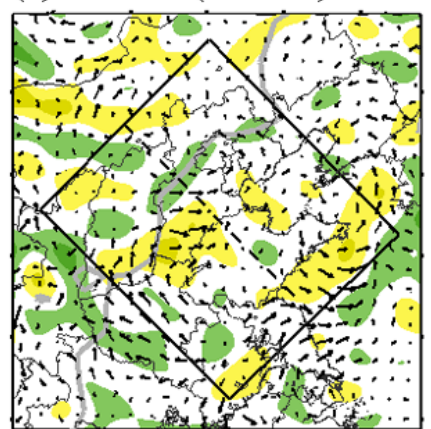

(f) 12UTC (20BST)

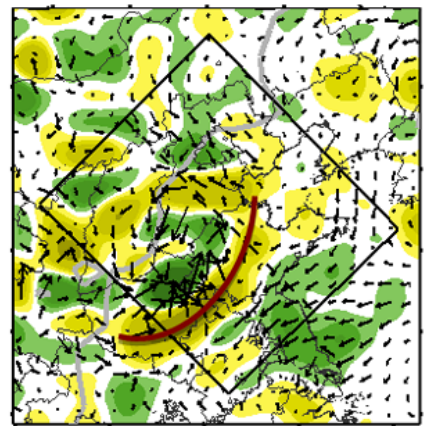

(i) 21UTC (05BST)

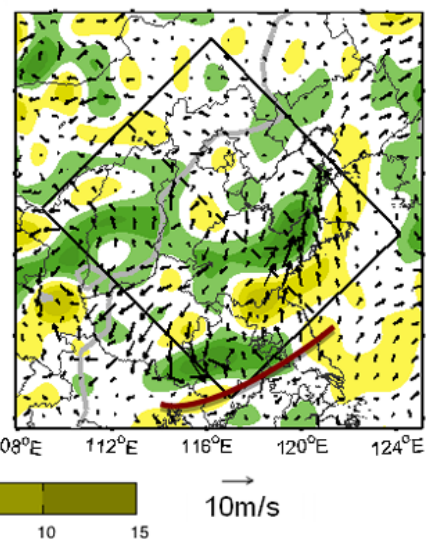

Fig. 7. (a) The average vertical velocity (shaded, $\mathrm{cm} \mathrm{s}^{-1}$ ) and horizontal wind vectors at $3 \mathrm{~km}$ a.g.l. for CNTL. The diurnal variation of the deviations from these averages are plotted for (b) 00:00 UT; (c) 03:00 UT; (d) 06:00 UT; (e) 09:00 UT; (f) 12:00 UT; (g) 15:00 UT; (h) 18:00 UT; (i) 21:00 UT. The thick maroon line denotes the location of the phase fronts of the updraft.

forms a cold pool near the surface behind the main updraft U1. A horizontal pressure gradient force (PGF) is produced because the pressure in the cold pool is much higher than that of the warm moist air to the southeast in the main updraft U1. Although the southeastward movement of convection is primarily due to the mid-tropospheric steering-level flow (HZ10), the PGF contributes to accelerating the main updraft U1 southeastward as well. Away from the old convection, some new convection is triggered by PGF and grows in front of the main updraft $\mathrm{U} 1$. This is somewhat reminiscent of Wang et al. (2011), who found that the forward-directed horizontal PGF caused acceleration further downstream near the surface and triggered new convection remotely. The complex interaction between the cold pool and the warm moist air in the updraft further enhances the vertical motion, yielding even stronger precipitation. At this time, a secondary updraft $\mathrm{U} 2$ is still located near the southeast slope of mountains but is no longer the main part of the MPS, and thus this secondary updraft $\mathrm{U} 2$ has no distinct contribution to the diurnal precipitation.

During the evening hours (12:00 UT, or 20:00 BST, Fig. 8f), the two updrafts and the downdraft continue propagating southeastward. The main updraft U1 and the downdraft arrive in the central plains and are enhanced due to 
(a) average

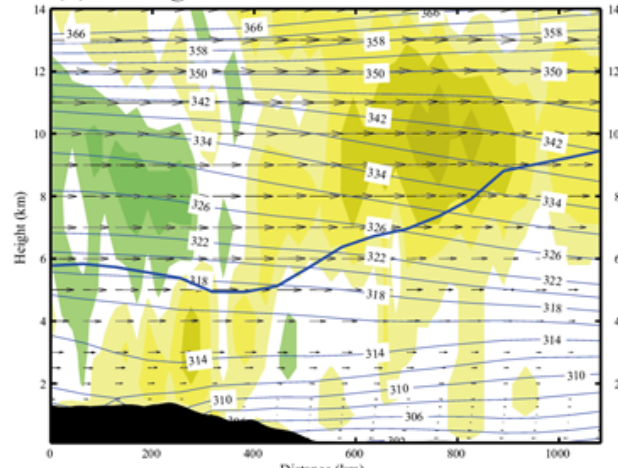

(d) 06UTC (14BST)

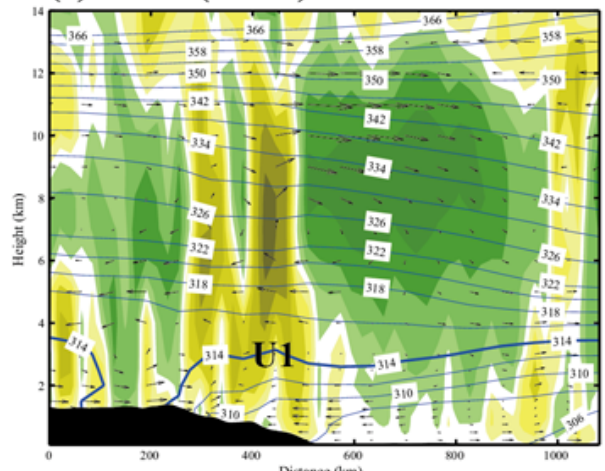

(g) 15UTC (23BST)

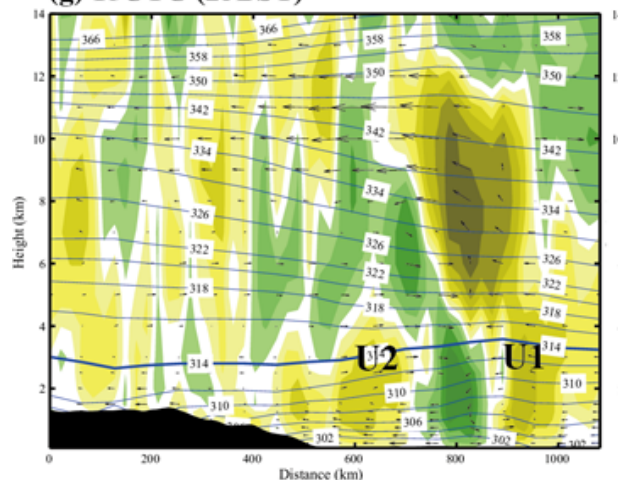

(b) 00UTC (08BST)

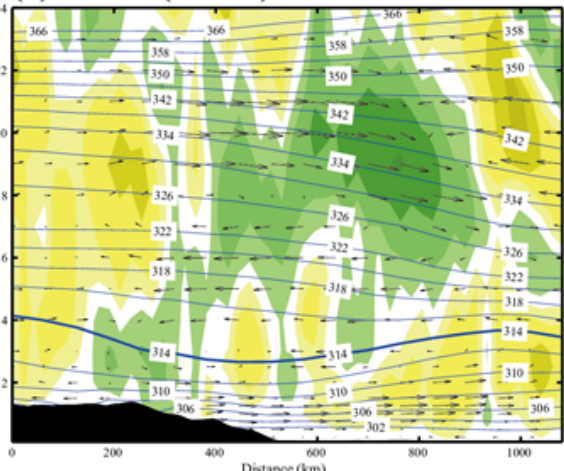

(e) 09UTC (17BST)

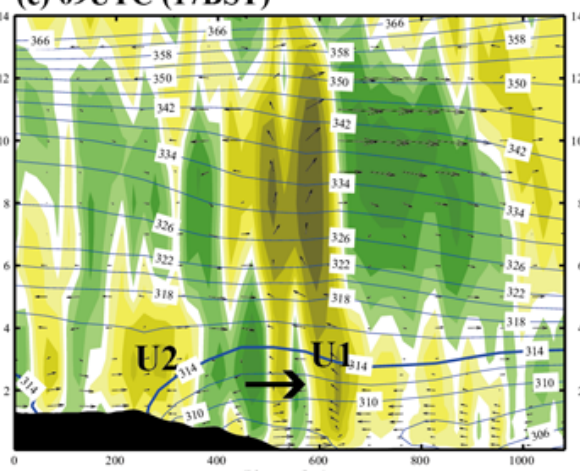

(h) 18UTC (02BST)

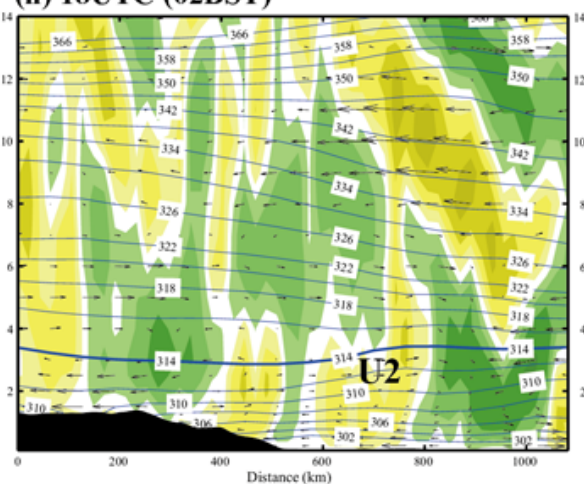

(c) 03UTC (11BST)

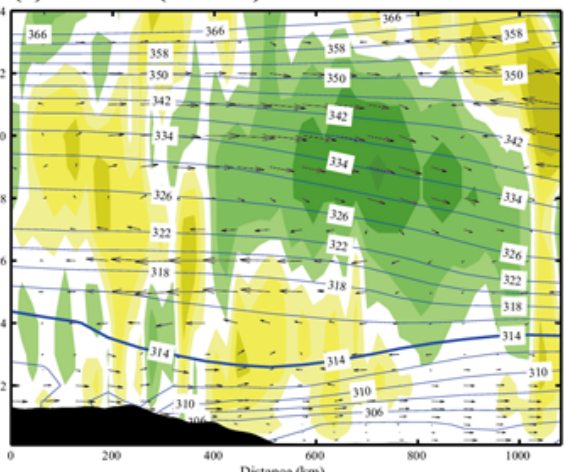

(f) 12UTC (20BST)

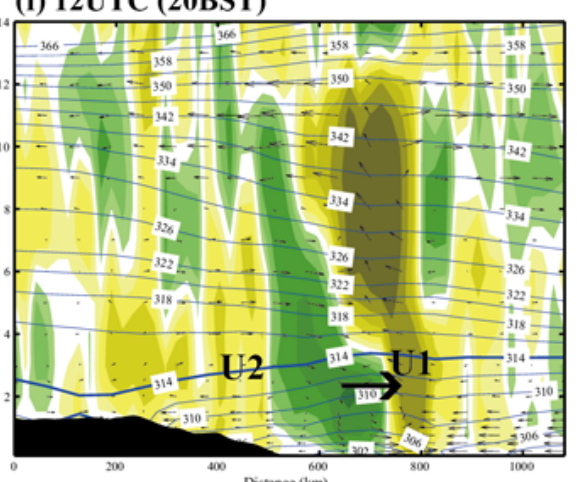

(i) 21UTC (05BST)

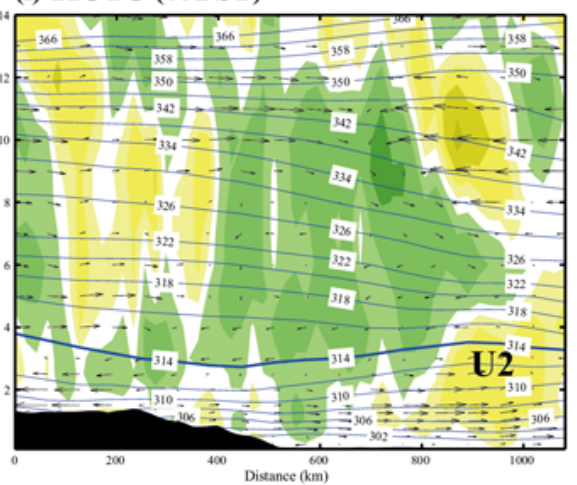

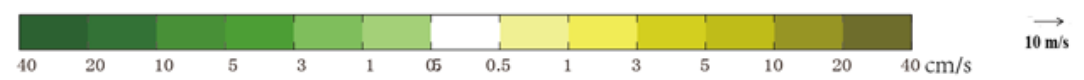

Fig. 8. (a) Height-distance cross section of daily mean potential temperature (solid lines, K), vertical velocity (shaded, $\mathrm{cm} \mathrm{s}^{-1}$ ) and the mean circulation vectors (horizontal wind component along the northwest-southeast cross section and 100 times the vertical velocity) averaged over ABEF from CNTL. The thick blue line shows where the northwesterly wind is equal to $12 \mathrm{~m} \mathrm{~s}^{-1}$. (b-i) As in (a) except that the vertical velocity and circulation vectors are the diurnal perturbations from the daily mean (potential temperature contours are of their full values). The black shading represents topography. The thick blue lines show that the potential temperature value is equal to $314 \mathrm{~K}$ in (b-i). The arrows show the pressure gradient force (PGF). U1 and U2 represent the main updraft and the secondary updraft, respectively.

increased precipitation, whereas the secondary updraft $\mathrm{U} 2$ arrives at the northwest edge of the plains and weakens. With the cessation of surface solar heating, there is only outgoing longwave radiation, which serves to weaken the temperature gradient between the mountains and the plains. Just before midnight (15:00 UT, or 23:00 BST, Fig. 8g), the main updraft/downdraft couplet moves to the southeastern plains and continues to weaken, resulting in a reduction of precipitation. Additionally, because the mountains cool faster than the plains, the direction of the temperature gradient reverses; this reversal causes the enhancement of the secondary updraft U2 over the northwestern plains and the appearance of a weak downdraft near the mountains, signaling the development of the nighttime pattern of the MPS. 
In the early morning of the second day (18:00 UT, or 02:00 BST, Fig. 8h), the main updraft U1 dissipates and moves out of the focus domain. In the meantime, a broad region of updraft begins to span over the northwestern plains while a downdraft develops over eastern edge of the mountains, signaling that the nighttime pattern is fully established. A few hours before sunrise (21:00 UT, or 05:00 BST, Fig. 8i), the MPS is still in the nighttime pattern, and the broad updraft moves to the southeastern plains.

Hovmöller diagrams of the mean vertical velocity at 3 and $6 \mathrm{~km}$ (Fig. 9a and b) from CNTL show that the diurnal characteristics of vertical velocity change greatly with height. At $3 \mathrm{~km}$, two parallel upward motion lines are present in the focus domain, separated by $\sim 300 \mathrm{~km}$ in horizontal distance and $\sim 6 \mathrm{~h}$ in time; both lines originate near the mountains and then move southeastward. The main updraft shows similar characteristics to the diurnal precipitation peaks. At $6 \mathrm{~km}$, the secondary (weaker) updraft line gradually weakens before finally fading away. Meanwhile, the main upward velocity belt becomes stronger at $6 \mathrm{~km}$ than it is at $3 \mathrm{~km}$. A local upward velocity belt that is separate from the main updraft appears over the southeast part of the plains in the afternoon (06:0012:00 UT, or 14:00-20:00 BST) and is quite evident at $6 \mathrm{~km}$. Consequently, the vertical velocity over the southeast domain of the plains has two diurnal peaks (i.e., a semi-diurnal variation). The feature of the diurnal vertical velocities at $6 \mathrm{~km}$ closely fits that of the diurnal precipitation peaks.

In summary, the main updraft branch of the MPS originates near the top of the Taihangshan Mountain Range in the afternoon during the strongest solar heating (around 06:00 UT, or 14:00 BST, in the afternoon), and then propagates southeastward at an average speed of $12 \mathrm{~m} \mathrm{~s}^{-1}$. Diurnal precipitation occurs behind the updraft, and the precipitationinduced downdraft divides the updraft into two parts (unlike the simple feature shown in HZ10). While the main updraft U1 progresses to the lee of the mountains, the secondary updraft U2 remains located near the southeast slope of the mountains in the late afternoon (09:00 UT, or 17:00 BST) before following the main updraft southeastward with a lag of $6 \mathrm{~h}$ and $300 \mathrm{~km}$. The main updraft U1 is the primary factor for the initiation of precipitation. The latent heat released when the main updraft U1 lifts warm moist air enhances the vertical motion, resulting in increased precipitation. Evaporating precipitation behind the main updraft forms a cold pool that interacts with warm moist air to the southeast, which also promotes precipitation. Furthermore, on the one hand, the PGF caused by the cold pool (with more dense air) can push the main updraft (with less dense air) towards the southeast, and, on the other hand, the PGF can induce new convection.

Related work by Koch et al. (2001) used numerical simulations to explore the role of a MPS in the generation of a second wave episode during the Cooperative Convective Precipitation Experiment. The results of our current control experiment are generally consistent with the findings of their study. Their MM5 control simulation clearly shows the development of a pronounced MPS over the Rocky Mountains due to differential solar heating. A strong MPS updraft originated near the mountaintop in the afternoon and then moved downslope, accelerating to a propagation speed of $\sim 11 \mathrm{~m} \mathrm{~s}^{-1}$ as the associated rearward cold pool/density current - which was produced by a rainband generated along the MPS leeward updraft/convergence zone - accelerated down the mountainside under the pressure gradient force. Nevertheless, there are obvious differences between these two studies. Koch et al. (2001) showed that the density current behind the MPS updraft - both of which were propagating eastward - merged with a separate, westward-propagating density current to produce an even stronger cold pool that pushed the greatly strengthened updraft eastward (under the steering level flow).

Our control experiment reproduces the evolution process of the MPS circulation. The MPS circulation possesses apparent diurnal variations, and has an important influence on the diurnal cycle of local precipitation. The MPS circulation is in its daytime peak pattern during the afternoon when the solar heating is maximized (around 06:00 UT, or 14:00 BST), with the updraft on the lee of the mountains and the downdraft over the plains; the process reverses to the nighttime peak pattern, when surface radiative cooling is much stronger over the mountains than the plains (around 21:00 UT, or 05:00 BST).

\section{Impact of latent heating and cooling on the development of convection}

The CNTL experiment indicates that convection is first triggered by the MPS updraft induced by differential diabatic heating/cooling. Convection grows deeper after precipitation happens, and subsequently propagates from the lee side to the plains due to the southeastward movement of the upward branch of the MPS along with the cold pool dynamics. The above analysis shows that latent heating and (to a much greater extent) cooling are responsible for the development and propagation of the convective system. The evaporative cooling from precipitation produces the cold pool, which enhances the precipitation while moving the updraft and rainfall belt southeastward. The Fake-dry and NOVAP experiments are run to analyze how the latent heating/cooling and cold pool influence the development and propagation of convection and the associated precipitation. The results of the 10 consecutive simulations from Fake-dry and NOVAP are averaged every hour individually to get the diurnal characteristics of the environmental and precipitation fields. The 10 consecutive runs are used instead of one continuous simulation in CNTL to ensure that the synoptic flow patterns in Fake-dry and NOVAP do not differ greatly from CNTL.

The daily precipitation from the two sensitivity experiments is shown in Fig. $4 \mathrm{c}$ and d. As discussed before, the precipitation decreased drastically in Fake-dry and increased 


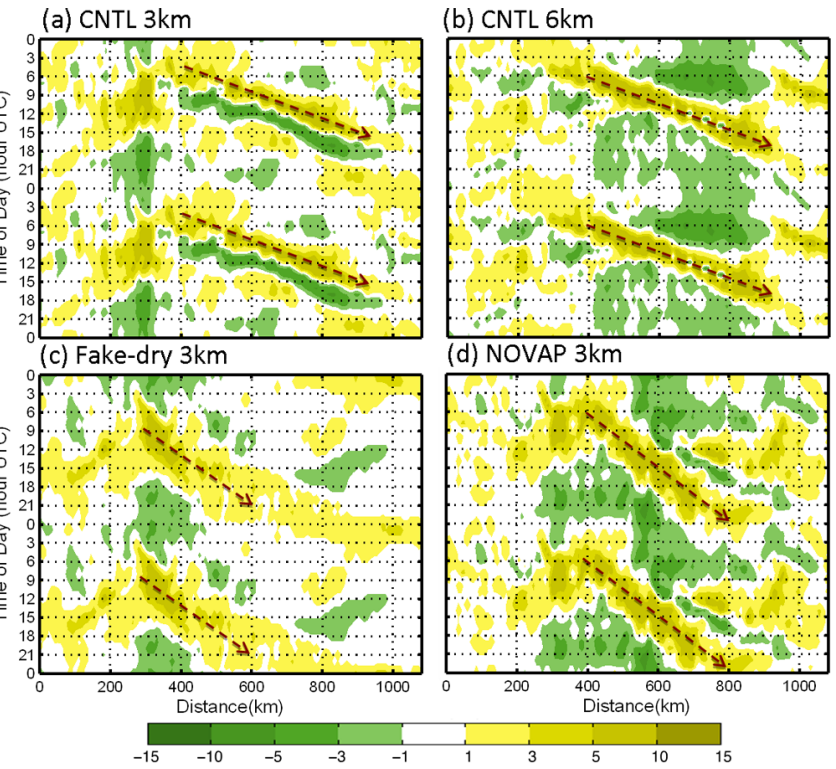

Fig. 9. Hovmöller diagrams of vertical velocity $\left(\mathrm{cm} \mathrm{s}^{-1}\right)$ at (a) $3 \mathrm{~km}$ of CNTL; (b) $6 \mathrm{~km}$ of CNTL; (c) $3 \mathrm{~km}$ of Fake-dry; (d) $3 \mathrm{~km}$ of NOVAP averaged along the northwest-southeast cross section through ABEF. The dashed arrows show the southeastward phase propagation of the updraft.

significantly in NOVAP compared with CNTL. Latent heating and cooling are the key factors of diurnal precipitation over northern China, especially over the plains. Hovmöller diagrams of the hourly rainfall averaged along the northwest-southeast cross section in ABEF from the two sensitivity experiments are shown in Fig. $6 \mathrm{c}$ and d. For Fake-dry (Fig. 6c), precipitation only occurs near the eastern slope of the mountains from the afternoon through the early morning of the next day (09:00 UT-00:00 UT, or 15:00 BST08:00 BST) without apparent downslope propagation. Precipitation for NOVAP (Fig. 6d) is different than CNTL in terms of location and intensity but has the characteristics of a southeastward propagation, albeit at about two-thirds the speed of CNTL. This implies that the cold pool plays an important role in the intensity of the precipitation and the distance of its southeastward propagation, whereas without any latent heating or cooling there will be no diurnal propagation of the precipitation.

The height-distance cross sections of potential temperature and the mean and anomalous three-dimensional circulation in ABEF from sensitivity experiments Fake-dry and NOVAP are shown in Figs. 10 and 11, respectively; Hovmöller diagrams of the mean vertical velocity at $3 \mathrm{~km}$ from these two experiments are shown in Fig. 9c and d. Figures 10a and 11a reveal the vertical structure of the averaged circulations from Fake-dry and NOVAP, respectively; each sensitivity experiment preserves some features of the CNTL MPS circulation. The vertical circulation from Fake-dry is similar to that of
CNTL, with the updraft over the mountains and very weak ${ }^{3}$ downdraft over the plains. For NOVAP, on the other hand, there is a remarkably strong updraft over almost the entire domain except at mid-levels over the mountains.

The diurnal variations in the vertical circulations of Fakedry (Figs. 9c and 10b-i) and NOVAP (Figs. 9d and 11b-i) are substantially different from CNTL (Figs. 8b-i and 9a). The distinct differences between Fake-dry and CNTL first appear in the late afternoon (09:00 UT, or 17:00 BST): unlike the two strong updrafts found in CNTL, there is only one weaker and slower-moving distinct updraft which barely reaches the center of the plains by the early morning of the second day (21:00 UT, or 05:00 BST). The sole updraft in this experiment matches closely with the trailing updraft in CNTL before 12:00 UT (20:00 BST), except that the mean propagation speed is $\sim 6 \mathrm{~m} \mathrm{~s}^{-1}$, which is about half of that in CNTL. In other words, the cold pool in CNTL acts to divide the MPS updraft into two parts and to push the precipitation southeastward while enhancing the precipitation by forcing a new updraft along its leading edge. It is worth noting that the system in Fake-dry propagates at about half the speed of that in CNTL from the top of the mountains (around $250 \mathrm{~km}$ ) to the foot (around $600 \mathrm{~km}$ ), which implies that the significant sloping terrain provides synergy on the system propagation.

The influence of cold pool dynamics on the organization and propagation of mesoscale convective systems is consistent with many past studies (e.g., Coniglio et al., 2012; Morrison et al. 2012) that can be traced back to the RotunnoKlemp-Weiman (RKW) theory (Rotunno et al., 1988). The RKW theory argues the importance of both the environmental vertical wind shear and the density current (i.e., cold pool) in maintaining the circulation of the squall lines and associated mesoscale convective systems (Rotunno et al., 1988; Weisman and Rotunno, 2004; Bryan et al., 2006). The RKW theory may be applicable to CNTL. The cold pool in the leading edge of the updraft eventually becomes more intense than the vertical wind shear that resulted in the updraft leaning upshear, which subsequently moves southwestward with the cold pool.

For NOVAP, the vertical circulation reveals some explicit features of the diurnal variation of the convective system found in CNTL, but has a much stronger updraft. Similar to CNTL, the MPS updraft appears near the lee of the mountains at 06:00 UT (14:00 BST) and then propagates southeastward towards the eastern part of the plains at a speed of $\sim 9 \mathrm{~m} \mathrm{~s}^{-1}$. Furthermore, in line with Fake-dry, there is neither a secondary updraft nor a cold pool. Nevertheless, the NOVAP experiment retains very clear signals of the MPS structure and the diurnal variation. Temperatures in NOVAP increase faster than both CNTL (because evaporative cooling is turned off) and Fake-dry (because latent heating is turned on). The higher temperatures enhance the development of

\footnotetext{
${ }^{3}$ It is only seen in the vector field with a magnitude smaller than the first negative value contoured in Fig. 8a.
} 
(a) average

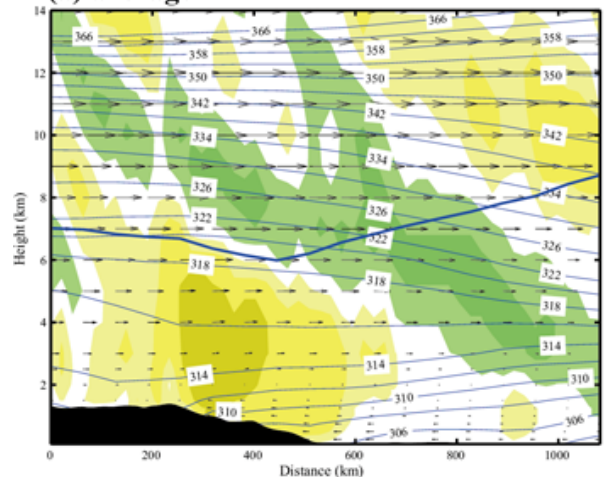

(d) 06UTC (14BST)

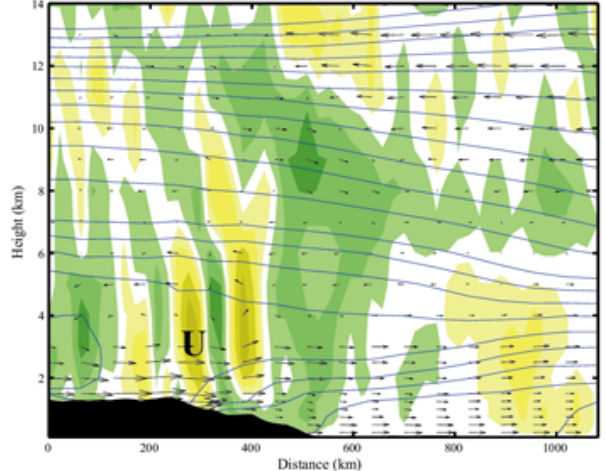

(g) 15UTC (23BST)

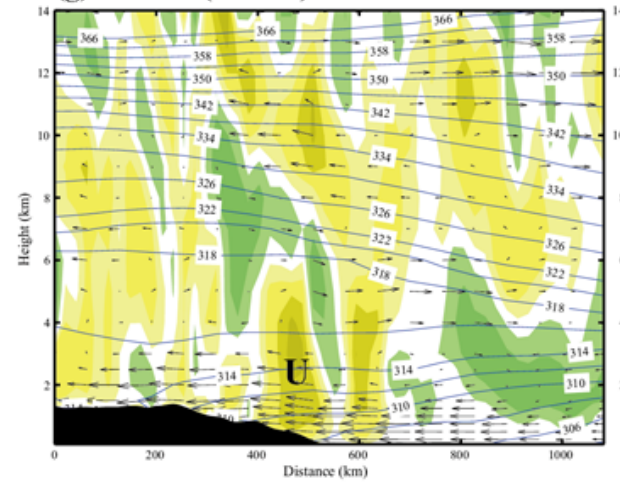

(b) 00UTC (08BST)

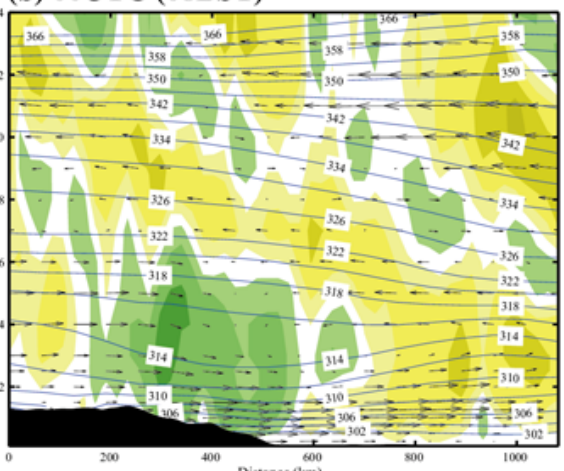

(e) 09UTC (17BST)

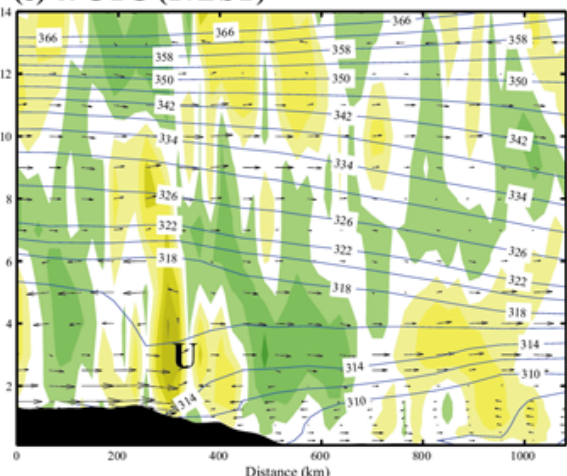

(h) 18UTC (02BST)

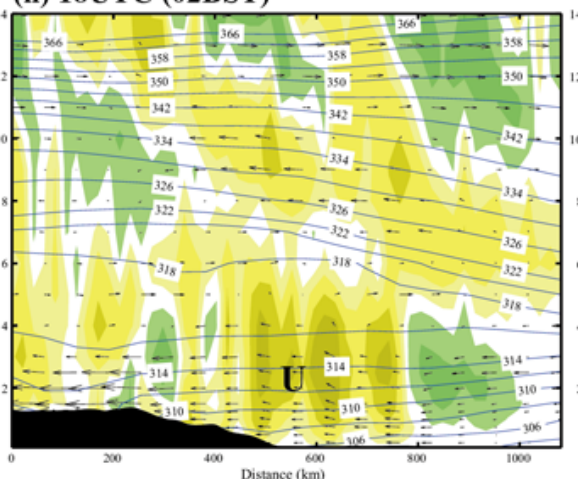

(c) 03UTC (11BST)

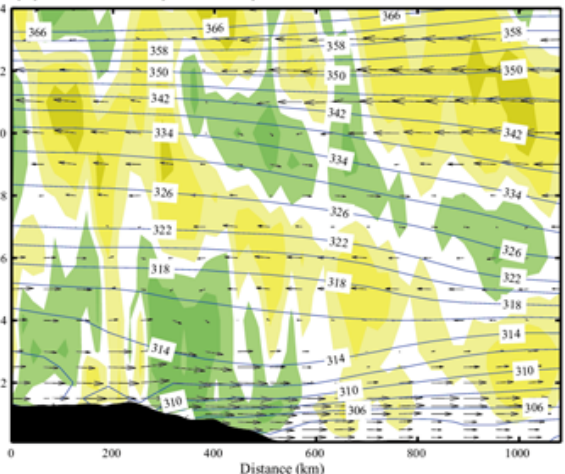

(f) 12UTC (20BST)

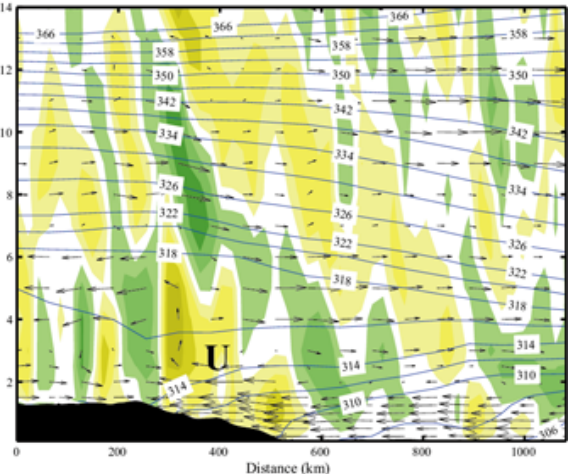

(i) 21UTC (05BST)

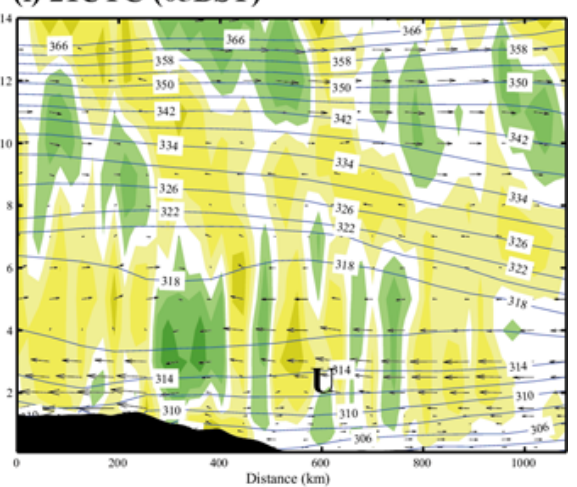

$\overrightarrow{10 \mathrm{~m} / \mathrm{s}}$

Fig. 10. As in Fig. 8, but for Fake-dry experiment.

local convection, and are the cause of the stronger updrafts over the central and eastern parts of the plains. The negative effects of the evaporative cooling on the intensity of convective precipitation were also indicated in Schumacher (2009) and Trier et al. (2011). The stronger precipitation in NOVAP can thus be attributed to a stronger updraft due to less energy loss by evaporative cooling, along with a smaller moving speed due to the lack of cold pool by turning off evaporative cooling, and more precipitation reaching the ground without evaporative cooling.
Under similar synoptic flow patterns with the same solar heating cycle, both Fake-dry and NOVAP preserve some of the diurnal variations found in CNTL, with the peak daytime pattern in the afternoon and the peak nighttime pattern at night. Nevertheless, without the cold pool, the updraft is much stronger and moves downslope much more slowly. This is consistent with the control and fake-dry simulations of Koch et al. (2001) in their study of an MPS circulation and related precipitation over North America. The differences in the intensity of convection and the propagation speed of the MPS updraft between Fake-dry and NOVAP show that 
(a) average

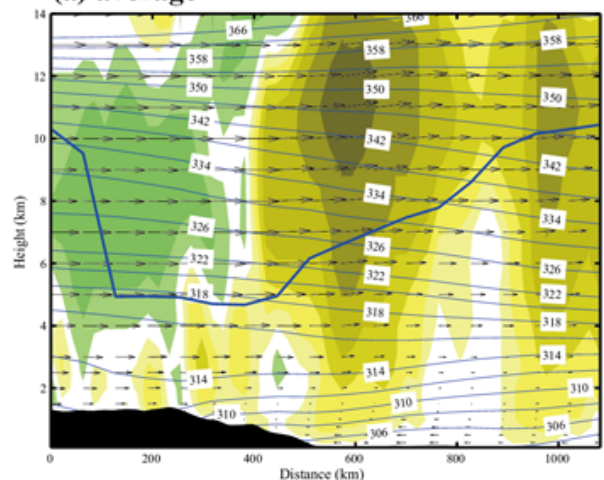

(d) 06UTC (14BST)

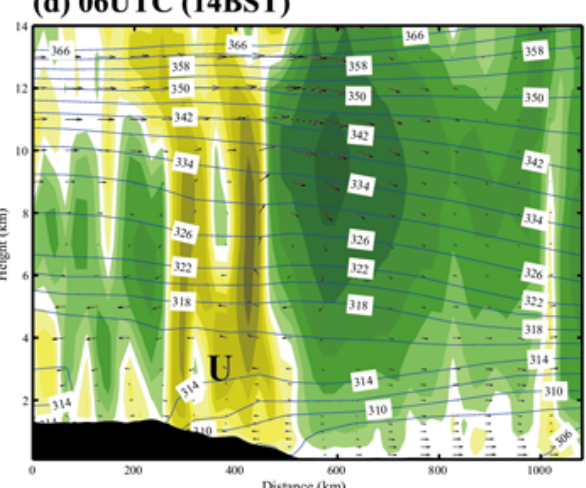

(g) 15UTC (23BST)

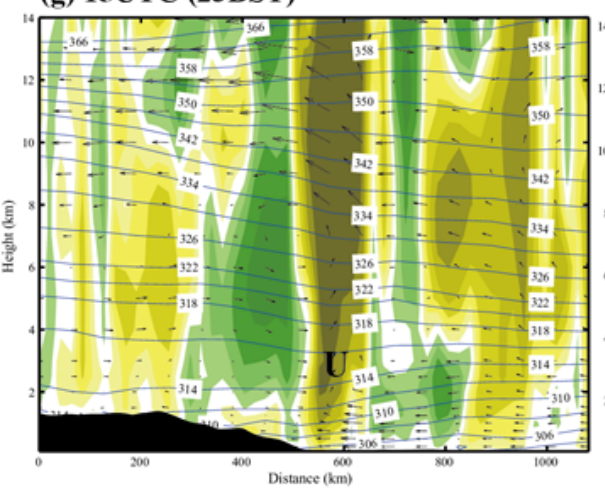

(b) 00UTC (08BST)

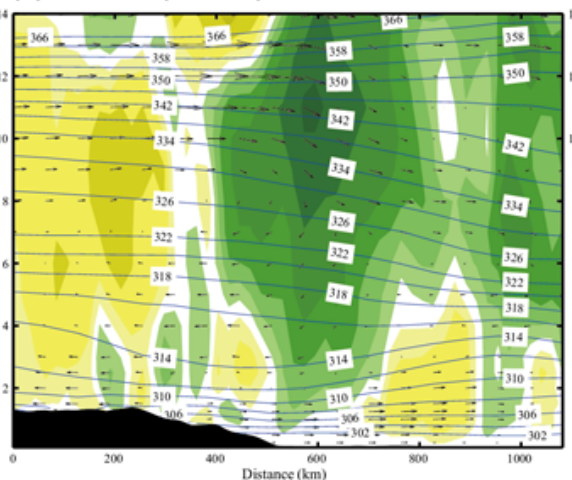

(e) 09UTC (17BST)

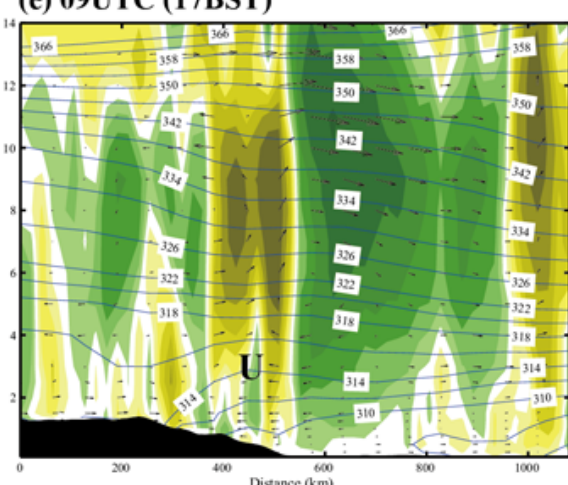

(h) 18UTC (02BST)

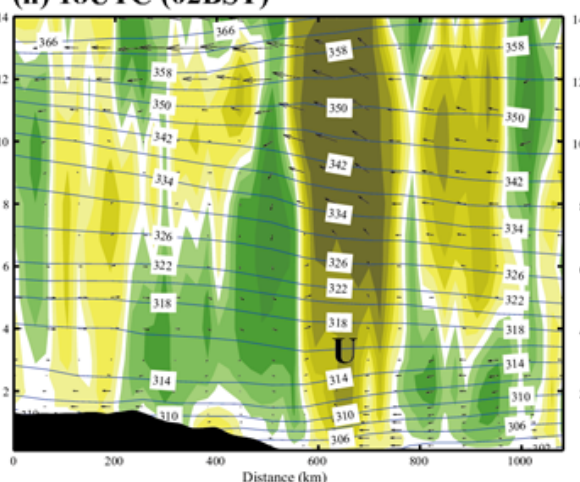

(c) 03UTC (11BST)

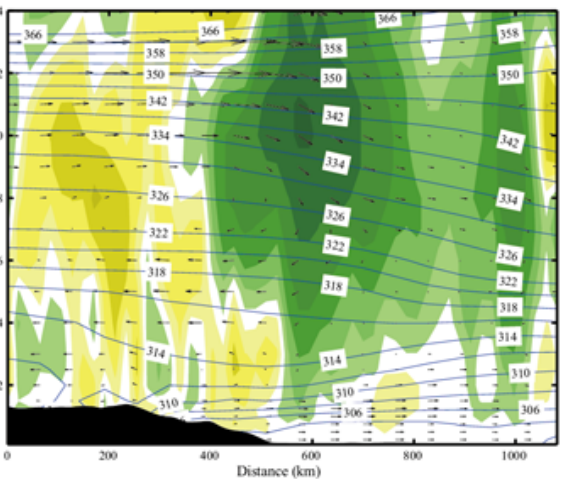

(f) 12UTC (20BST)

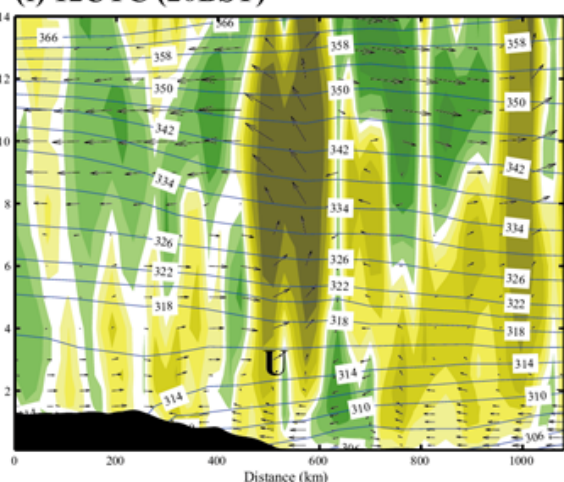

(i) 21UTC (05BST)

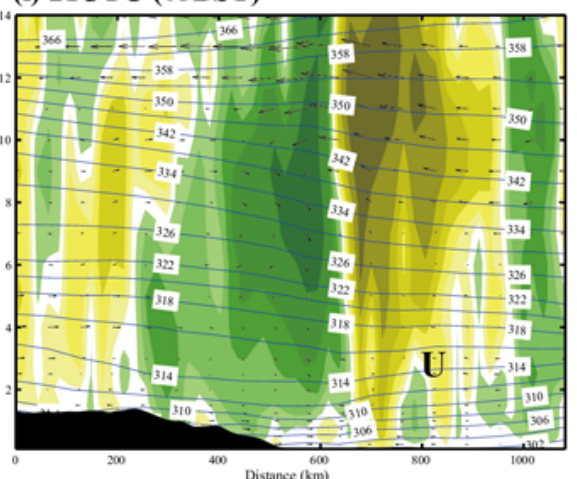

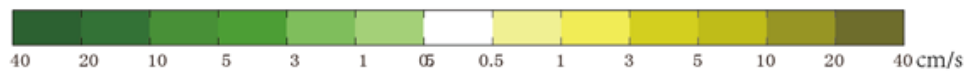

$\overrightarrow{10 \mathrm{~m} / \mathrm{s}}$

Fig. 11. As in Fig. 10, but for NOVAP experiment.

cooling from the evaporation of liquid water is the key factor in forming the cold pool, whereas latent heating plays an important role in the intensification and acceleration of the updraft.

Some past studies have also noted that the mid-level flow is one of the key factors influencing the propagation speed of the diurnal precipitation peak and the MPS updraft (HZ10; Bao et al., 2011). Figures 8a, 10a, and 11a show the vertical profiles of the mean three-dimensional circulation from experiments CNTL, Fake-dry and NOVAP, respectively. As said before, the speed of the southeastward propagation of the updraft in Fake-dry (NOVAP) decreases to only about half $(2 / 3)$ of that in CNTL. The thick blue lines are plotted to show where the northwesterly component of the wind is equal to $12 \mathrm{~m} \mathrm{~s}^{-1}$ (the propagation speed of the updraft in CNTL). In Fake-dry (NOVAP), the intensity of the midlevel wind is only slightly weaker (stronger) than CNTL over the mountains, where the $12 \mathrm{~m} \mathrm{~s}^{-1}$ isotach is near $6 \mathrm{~km}$ in CNTL, $7 \mathrm{~km}$ in Fake-dry, and $5 \mathrm{~km}$ in NOVAP. Over the plains, the $12 \mathrm{~m} \mathrm{~s}^{-1}$ isotach in CNTL is slightly higher (lower) than Fake-dry (NOVAP). It is clear from these plots that changes in mid-level winds are not the primary reason 
09 UTC (17 BST)
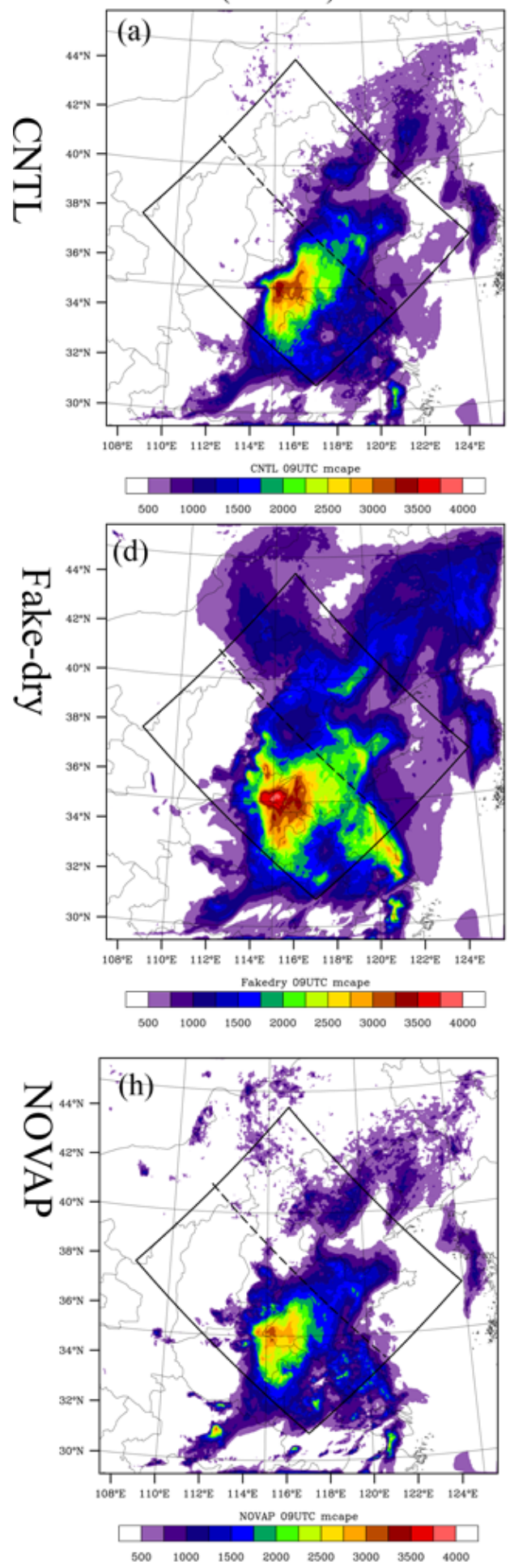

12 UTC (20 BST)
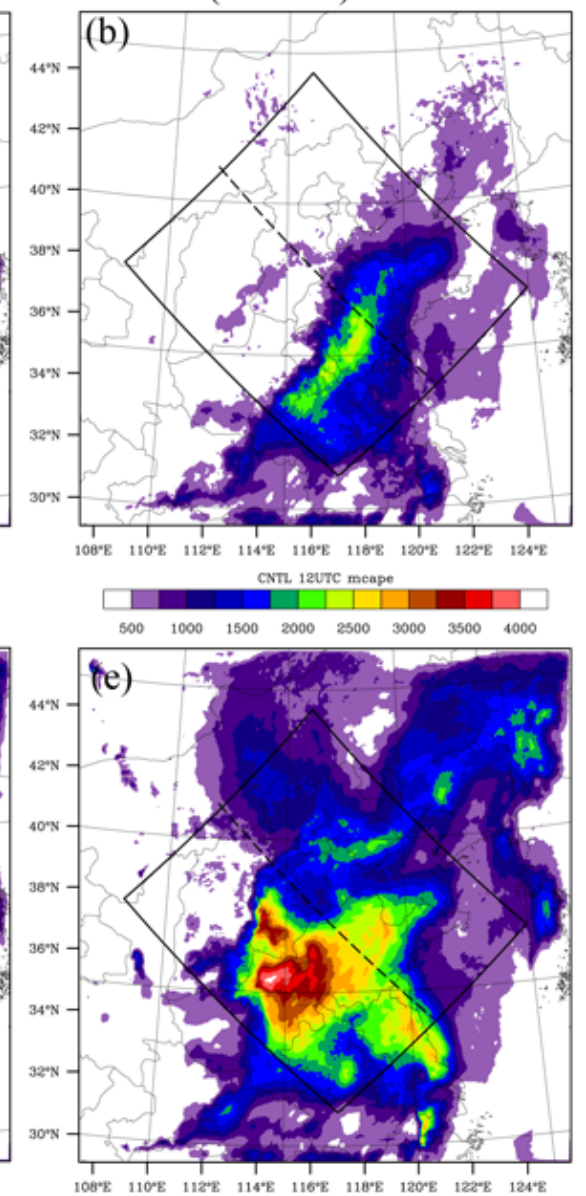

Fakedry 12 UTC meape
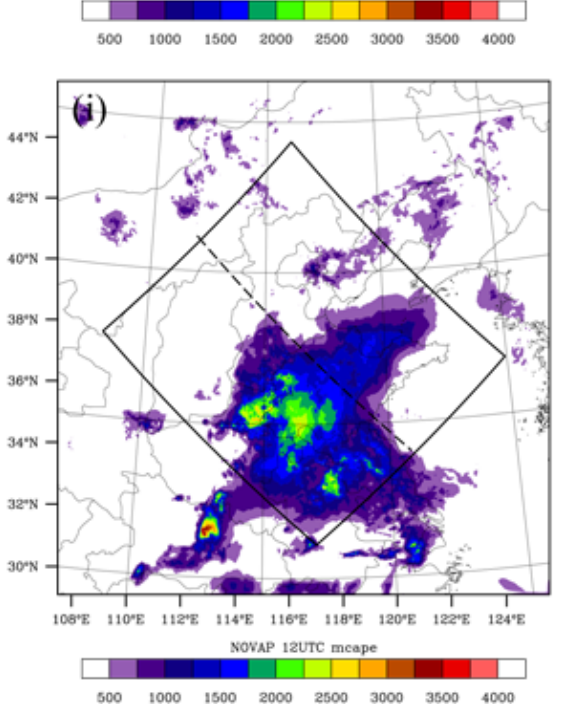

15 UTC (23 BST)
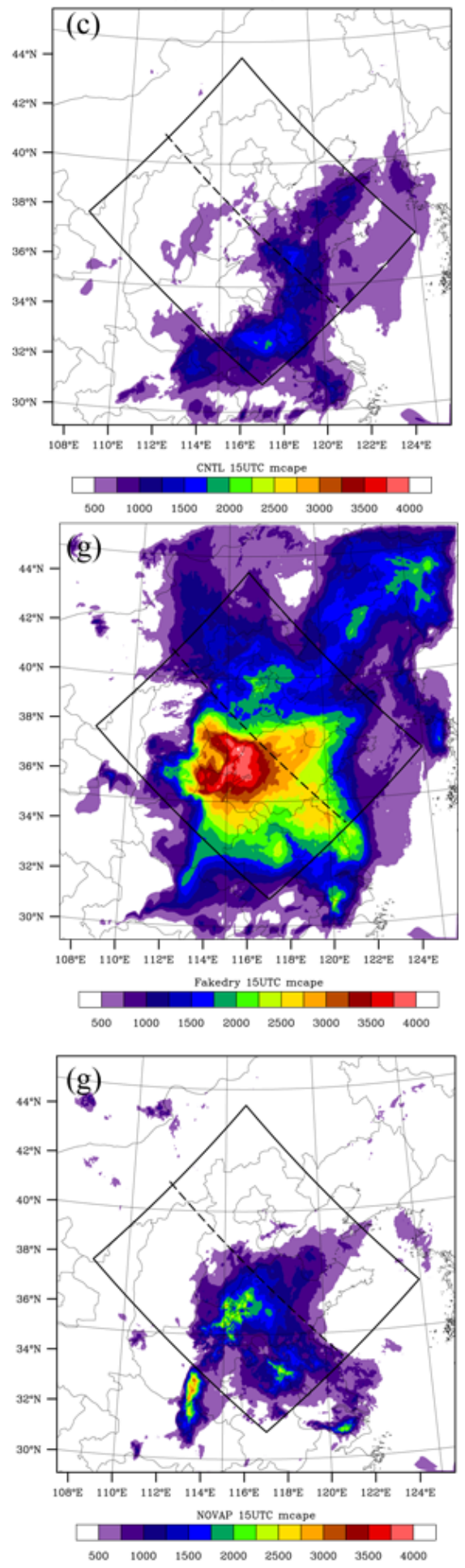

Fig. 12. The distribution of the averaged CAPE $\left(\mathrm{J} \mathrm{Kg}^{-1}\right.$ ) at 09:00 UTC, 12:00 UTC, and 15:00 UTC in CNTL (a-c), Fake-dry (d-f), and $\operatorname{NOVAP}(\mathbf{h}-\mathbf{g})$. 
for the differences in updraft propagation speed between the two sensitivity experiments and CNTL. This further demonstrates that the diurnally varying MPS induced by the differential surface sensible heating is the main factor for the generation and evolution of the convective system, but plays the secondary role in the propagation of precipitation. Conversely, latent heating and cooling can enhance the convection and modulate its propagation. To sum up, apart from the mid-level steering flow and the pressure gradient force produced by the cold pool, the mountain slope and the divergent outflow may have also contributed to the propagation of the convective system propagation.

Figure 12 shows the spatial distributions of the 10-day averaged maximum convective available potential energy (CAPE) at 09:00 UT, 12:00 UT, and 15:00 UT for all three experiments. Counterintuitively, Fake-Dry has the largest CAPE yet produces the least precipitation, while CNTL and NOVAP have a more or less similar amount of CAPE over the plains before the arrival of the convection. The larger amount of CAPE in Fake-Dry than CNTL is due to the artificial suppression of the convective potential energy release (and thus more accumulation) by turning off latent heating release. We also compared other mean thermodynamic conditions and the stability indices of the atmosphere over the plains among the three experiments (not shown), but for the same reasons (artificial suppression of convection or turning off evaporative cooling) none of these measures provides obvious explanations of the difference in the precipitation amount. As discussed in earlier text, the updraft has the smallest amplitude in Fake-Dry, which leads to the least amount of precipitation. Although the stability condition (and CAPE) is similar between CNTL and NOVAP, without the cooling due to evaporation, NOVAP may attain higher amplitude of updrafts that can enhance the precipitation rate, consistent with some previous studies (e.g., Schumacher, 2009; Trier et al., 2011). Moreover, without the cold pool from evaporative cooling in NOVAP, the updraft will move much slower. A slowermoving but stronger updraft will further enhance the local accumulated precipitation in NOVAP more than in CNTL.

\section{Concluding remarks}

This study follows HZ10 and examines the impact of the mountain-plains solenoid (MPS) circulation on the diurnal cycle of warm-season precipitation over northern China. Using high-resolution WRF simulations over several days, this study examines in detail the diurnal variations of precipitation and the MPS circulation.

The base period is 17-24 June 2004, which featured several episodes of southeastward-propagating precipitation over northern China that originated from the "second-step" mountain ranges and moved to the "third-step" plains with an apparent diurnal cycle. The control experiment (CNTL) is a 15-day simulation that uses the 8-day average of the NCEP
GFS gridded analyses at 00:00 UT for the initial conditions and the 8-day averages at 00:00 UT, 06:00 UT, 12:00 UT and 18:00 UT for the lateral boundary conditions (to allow for diurnal variations). In addition to the control experiment, two sensitivity experiments are performed to better understand the roles of evaporative cooling (for cold pool formation) and latent heating on the evolution of the MPS circulation.

Despite differences in the rainfall intensity and location, the control experiment successfully simulated the diurnal variation of precipitation and southeastward propagation of the peak phase of the diurnal precipitation from the lee of Yanshan-Taihangshan mountain ranges to the North China Plain (which have been presented in HZ10). The diurnal precipitation peak initiates on the lee of mountain ranges in the afternoon (06:00 UT, or 14:00 BST) at the time of maximum solar heating and then propagates southeastward at a mean speed of $12 \mathrm{~m} \mathrm{~s}^{-1}$. The peak reaches the plains in the nighttime hours, reaching its maximum intensity over the central plains before midnight (12:00-15:00 UT, or 20:0023:00 BST), and has a lag of $3 \mathrm{~h}$ or $200 \mathrm{~km}$ compared with HZ10.

Using the coarse spatial and temporal resolution of the GFS analysis, HZ10 found that the MPS circulation is closely connected with the diurnal variation in the warm-season precipitation over northern China. In this study, CNTL captures (in high spatial and temporal resolution) the detailed evolutionary process of the MPS circulation. The MPS circulation possesses an apparent diurnal variation that is caused by the differential heating between mountains and plains, and has an important influence on the diurnal cycle of local precipitation. The MPS circulation is in the daytime peak pattern in the afternoon at the time of maximum solar heating, with the updraft over the lee of the mountains and the downdraft over the plains; the circulation then reverses to the nighttime peak pattern when the surface longwave cooling is much stronger over the mountains than over plains. The diurnal variation of the MPS circulation is shown to be the primary factor in the initiation and organization of convection. The main updraft initiates on the southeast slope of the mountains in the afternoon, with precipitation occurring behind the updraft; both features propagate southeastward towards the plains.

In an experiment that turned off all latent heating and cooling (Fake-dry), the MPS circulation was still generated and had the diurnal variations of the control. Nevertheless, the MPS updraft was much weaker and slower in propagating southeastward compared with CNTL. The cold pool is not produced without evaporative cooling, which is also the reason why the updraft moves more slowly and then halts on the central plains. In an experiment that only turned off cooling from the evaporation of liquid water (NOVAP), the MPS circulation was stronger than in CNTL but with a slowermoving updraft (although not as slow as Fake-dry). This result implies that latent heating plays an important role in determining the intensity of MPS circulation. The interaction between the cold pool and environment vertical wind shear 
(such as in the RKW theory) may lead to the longevity and maintenance of convection, while the pressure gradient force (PGF) produced by the heavy cold pool can accelerate the updraft southeastward-propagation. One the other hand, without the evaporative cooling, the updraft intensity could be stronger (without the net loss of energy) and slower (without the push by the cold pool by cooling), which may as a result enhance the local precipitation. The current study complements recent studies on the relationship between the MPS circulation and the diurnal variation of warm-season precipitation over the large-scale mountains and adjacent plains (HZ10, Bao et al., 2011; Sun and Zhang, 2012).

Acknowledgements. We are grateful to Yunqi Ni and Jianhua Sun for comments and suggestions. Proofreading by Benjamin Green is greatly appreciated. The authors are also thankful for computing support by the Texas Advanced Computing Center (TACC). This study is partially sponsored by US NSF Grant 0904635, National Basic Research Program of China (973 Program) Grant 2012CB417205, and Basic Research Fund of the Chinese Academy of Meteorological Sciences Grant 2010Y002.

Edited by: G. Vaughan

\section{References}

Asai, T., Ke, S., and Kodama, Y.: Diurnal variability of cloudiness over East Asia and the Western Pacific Ocean as revealed by GMS during the warm season, J. Meteorol. Soc. Jpn., 76, 675684, 1998

Bao, X., Zhang, F., and Sun, J.: Diurnal variations of warm-season precipitation east of the Tibetan Plateau over China, Mon. Rev., 139, 2790-2810, 2011.

Bryan, G. H., Knievel, J. C., and Parker, M. D.: A multimodel assessment of RKW theory's relevance to squall-line characteristics, Mon. Rev., 134, 2772-2792, 2006.

Carbone, R. E. and Tuttle, J. D.: Rainfall occurrence in the US warm season: the diurnal cycle, J. Climate, 21, 4132-4136, 2008.

Carbone, R. E., Tuttle, J. D., Ahijevych, D., and Trier, S. B.: Inferences of predictability associated with warm season precipitation episodes, J. Atmos. Sci., 59, 2033-2056, 2002.

Chen, G., Sha, W., and Iwasaki, T.: Diurnal variation of precipitation over southeastern China: Spatial distribution and its seasonality, J. Geophys. Res., 114, D13103, doi:10.1029/2008JD011103, 2009a.

Chen, G., Sha, W., and Iwasaki, T.: Diurnal variation of precipitation over southeastern China: 2. Impact of the diurnal monsoon variability, J. Geophys. Res., 114, D21105, doi:10.1029/2009JD012181, 2009b.

Coniglio, M. C., Corfidi, S. F., and Kain, J., S.: Views on applying RKW theory: an illustration using the 8 May 2009 derechoproducing convective system, Mon. Rev., 140, 1023-1043, 2012.

Dai, A.: Global precipitation and thunderstorm frequencies, Part II: Diurnal variations, J. Climate, 14, 1112-1128, 2001.

Dai, A. and Trenberth, K. E.: The diurnal cycle and its depiction in the Community Climate System Model, J. Climate, 17, 930-951, 2004.
Dai, A., Giorgi, F., and Trenberth, K. E.: Observed and modelsimulated diurnal cycles of precipitation over the contiguous US, J. Geophys. Res., 104, 6377-6402, 1999.

Dudhia, J.: Numerical study of convection observed during the winter monsoon experiment using a mesoscale two-dimensional model, J. Atmos. Sci., 46, 3077-3107, 1989.

Fitzjarrald, D. R., Sakai, R. K., Moraes, O. L. L., Cosme de Oliveira, R., Acevedo, O. C., Czikowsky, M. J., and Beldini, T.: Spatial and temporal rainfall variability near the Amazon-Tapajós confluence, J. Geophys. Res., 113, G00B11, doi:10.1029/2007JG000596, 2008.

Fujinami, H., Nomura, S., and Yasunari, T.: Characteristics of diurnal variations in convection and precipitation over the Southern Tibetan Plateau during summer, SOLA, 1, 49-52, 2005.

He, H. and Zhang, F.: Diurnal variations of warm-season precipitation over Northern China, Mon. Rev., 138, 1017-1025, 2010.

Hirose, M. and Nakamura, K.: Spatial and diurnal variation of precipitation systems over Asia observed by the TRMM Precipitation Radar, J. Geophys. Res., 110, D05106, doi:10.1029/2004JD004815, 2005.

Hong, S.-Y. and Lim, J. -O. J.: The WRF single-moment microphysics scheme (WSM6), J. Korean Meteor. Soc., 42, 129-151, 2006.

Hong, S.-Y., Noh, Y., and Dudhia, J.: A new vertical diffusion package with an explicit treatment of entrainment processes, Mon. Rev., 134, 2318-2341, 2006.

Hu, K., Lu, R., and Wang, D.: Seasonal climatology of cut-off lows and associated precipitation patterns over Northeast China, Meteorol. Atmos. Phys., 100, 291-301, 2010.

Huang, H. L., Wang, C. C., Chen, G. T. J., and Carbone, R. E.: The role of diurnal solenoidal circulation on propagating rainfall episodes near the Eastern Tibetan Plateau, Mon. Rev., 138, 2975 2989, 2010.

Joyce, R. J., Janowiak, J. E., Arkin, P. A., and Xie, P.: CMOPRH: A method that produces global precipitation estimates from passive microwave and infrared data at high spatial and temporal resolution, J. Hydrometeorol., 5, 487-503, 2004.

Koch, S. E., Zhang, F., Kaplan, M. L., Lin, Y-L., Weglarz, R., and Trexler, C. M.: Numerical simulations of a gravity wave event over CCOPE. Part III: The role of a mountain-plains solenoid in the generation of the second wave episode, Mon. Rev., 129, 909-933, 2001.

Laing, A. G., Carbone, R. E., Levizzani, V., and Tuttle, J.: The propagation and diurnal cycles of deep convection in northern tropical Africa, Q. J. Roy. Meteor. Soc., 134, 93-109, 2008.

Laing, A. G., Trier, S. B., and Davis, C. A.: Numerical simulations of organized convection in tropical northern Africa, Mon. Rev., 140, 2874-2886, 2012.

Levizzani, V., Pinelli, F., Pasqui, M., Melani, S., Laing, A. G., and Carbone, R. E.: A 10-year climatology of warm-season cloud patterns over Europe and the mediterranean from meteosat IR observations, Atmos. Res., 97, 555-576, 2010.

Li, J., Yu, R., and Zhou, T.: Seasonal variations of the diurnal cycle of rainfall in the southern contiguous China, J. Climate, 21, 6036-6043, 2008.

Li, Y. and Smith, R. B.: Observation and theory of the diurnal continental thermal tide, J. Atmos. Sci., 67, 2752-2765, 2010.

Liang, X.-Z., Li, L., Dai, A., and Kunkel, K. E.: Regional climate model simulation of summer precipitation diurnal 
cycle over the USt, Geophys. Res. Lett., 31, L24208, doi:10.1029/2004GL021054, 2004.

Lin, X., Randall, D. A., and Fowler, L. D.: Diurnal variability of the hydrologic cycle and radiative fluxes: comparisons between observations and a GCM, J. Climate, 13, 4159-4179, 2000.

Mlawer, E. J., Taubman, S. J., Brown, P. D., Iacono, M. J., and Clough, S. A.: Radiative transfer for inhomogeneous atmospheres: RRTM, a validated correlated-k model for the longwave, J. Geophys. Res., 102, 16663-16682, 1997.

Morrison, H., Tessendorf, S. A., Ikeda, K., and Thompson, G.: Sensitivity of a simulated midlatitude squall line to parameterization of raindrop breakup, Mon. Rev., 140, 2437-2460, 2012.

Nober, F. J., Graf, H. F., and Rosenfeld, D.: Sensitivity of the global circulation to the suppression of precipitation by anthropogenic aerosols, Global Planet. Change, 37, 57-80, 2003.

Ohsawa, T., Ueda, H., Hayashi, T., Watanabe, A., and Matsumoto, J.: Diurnal variations of convective activity and rainfall in tropical Asia, J. Meteor. Soc. Japan, 79, 333-352, 2001.

Pritchard, M. S., Moncrieff, M. W., and Somerville, R. C. J.: Orogenic propagating precipitation systems over the US in a global climate model with embedded explicit convection, J. Atmos. Sci., 68, 1821-1840, 2011.

Rotunno, R., Klemp, J. B., and Weisman, M. L.: A theory for strong, long-lived squall lines, J. Atmos. Sci., 45, 463-485, 1988.

Schumacher, R. S.: Mechanisms for quasi-stationary behavior in simulated heavy-rain-producing convective systems, J. Atmos. Sci., 66, 1543-1568, 2009.

Shen, Y., Xiong, A., Wang, Y., and Xie, P.: Performance of highresolution satellite precipitation products over China, J. Geophys. Res., 115, D02114, doi:10.1029/2009JD012097, 2010.

Skamarock, W. C., Klemp, J. B., Dudhia, J., Gill, D. O., Barker, D. M., Duda, M. G., Huang, X. Y., Wang, W., and Powers, J. G.: A description of the Advanced Research WRF version 3. NCAR Tech. Note NCAR/TN-475+STR, 113 pp., available at: http:// www.mmm.ucar.edu/wrf/users/docs/arw_v3.pdf, 2008.

Sun, J. and Zhang, F.: Impacts of Mountain-plains solenoid on diurnal variations of rainfalls along the Mei-Yu Front over the East China plains, Mon. Rev., 140, 379-397, 2012.

Tao, S. Y. and Chen, L.-X.: A review of Recent Research on the East Asian summer Monsoon in China, Monsoon Meteorology, edited by: Chang, C.-P. and Krishnamurti, T. N., Oxford University Press, 60-92, 1987.

Trenberth, K. E., Dai, A., Rasmussen, R. M., and Parsons, D. B.: The changing character of precipitation, B. Am. Meteorol. Soc., 84, 1205-1217, 2003.

Trier, S. B., Davis, C. A., Ahijevych, D. A., Weisman, M. L., and Bryan, G. H.: Mechanisms supporting long-lived episodes of propagating nocturnal convection within a 7 day WRF model simulation, J. Atmos. Sci., 63, 2437-2461, 2006.

Trier, S. B., Davis, C. A., and Ahijevych, D. A.: Environmental controls on the simulated diurnal cycle of warm-season precipitation in the continental US, J. Atmos. Sci., 67, 1066-1090, 2010.
Trier, S. B., Marsham, J. H., Davis, C. A., and Ahijevych, D. A.: Numerical simulations of the postsunrise reorganization of a nocturnal mesoscale convective system during 13 June IHOP_2002, J. Atmos. Sci., 68, 2988-3011, 2011.

Tripoli, G. J. and Cotton, W. R.: An intense, quasi-steady thunderstorm over mountainous terrain, Part IV: three-dimensional numerical simulation, J. Atmos. Sci., 43, 894-913, 1986.

Tripoli, G. J. and Cotton, W. R.: Numerical study of an observed orogenic mesoscale convective system, Part II: Analysis of governing dynamics, Mon. Rev., 117, 305-328, 1989.

Wang, C. C., Chen, G. T. J., and Carbone, R. E.: A climatology of warm-season cloud patterns over East Asia based on GMS infrared brightness temperature observations, Mon. Rev., 132, 1606-1609, 2004.

Wang, C. C., Chen, G. T. J., and Carbone, R. E.: Variability of warm-season cloud episodes over East Asia based on GMS infrared brightness temperature observations, Mon. Rev., 133, 1478-1500, 2005.

Wang, C. C., Chen, G. T. J., and Huang, S. Y.: Remote trigger of deep convection by cold outflow over the Taiwan Strait in the Mei-yu season: A modeling study of the 8 June 2007 case, Mon. Rev., 139, 2854-2875, 2011.

Weisman, M. L. and Rotunno, R.: A theory for strong long-lived squall lines revisited., J. Atmos. Sci., 61, 361-382, 2004.

Wolyn, P. G. and McKee, T. B.: The Mountain-Plains circulation east of a 2-km-High North-South barrier, Mon. Rev., 122, 1490$1508,1994$.

$\mathrm{Xu}, \mathrm{W}$. and Zipser, E. J.: Diurnal variations of precipitation, deep Convection, and lightning over and east of the Eastern Tibetan Plateau, J. Climate, 24, 448-465, 2011.

Xu, W., Zipser, E. J., and Liu, C.: Rainfall characteristics and convective properties of mei-yu precipitation systems over South China, Taiwan and the South China Sea. Part I: TRMM observations, Mon. Rev., 137, 4261-4275, 2009.

Yang, G.-Y. and Slingo, J.: The diurnal cycle in the tropics, Mon. Rev., 129, 784-801, 2001.

Yu, R., Zhou, T., Xiong, A., Zhu, Y., and Li, J.: Diurnal variations of summer precipitation over contiguous China, Geophys. Res. Lett., 34, L01704, doi:10.1029/2006GL028129 2007a.

Yu, R., Xu, Y., Zhou, T., and Li, J.: Relation between rainfall duration and diurnal variation in the warm season precipitation over Central Eastern China, Geophys. Res. Lett., 34, L13703, doi:10.1029/2007GL030315, 2007b.

Zhang, C., Zhang, Q., Wang, Y., and Liang, X.: Climatology of warm season cold vortices in East Asia: 1979-2005, Meteorol. Atmos. Phys., 100, 291-301, 2008.

Zhang, F. and Koch, S. E.: Numerical simulation of a gravity wave event observed during CCOP E. Part 2: Wave generation by an orographic density current, Mon. Rev., 128, 2777-2796, 2000.

Zhou, T., Yu, R., Chen, H., Dai, A., and Pan, Y.: Summer precipitation frequency, intensity, and diurnal cycle over China: a comparison of satellite data with rain gauge observations, J. Climate, 21, 3997-4010, 2008. 